\title{
Stock Market Volatility: Examining North America, Europe and Asia
}

\author{
Lakshmi Bala $^{a}$ and Gamini Premaratne ${ }^{b}$ \\ National University of Singapore, Department of Economics
}

\begin{abstract}
An understanding of volatility in stock markets is important for determining the cost of capital and for assessing investment and leverage decisions as volatility is synonymous with risk. Substantial changes in volatility of financial markets are capable of having significant negative effects on risk averse investors. Using daily returns from 1992 to 2002, we investigate volatility co-movement between the Singapore stock market and the markets of US, UK, Hong Kong and Japan. In order to gauge volatility comovement, we employ econometric models of (i) Univariate GARCH (ii) Vector Autoregression and (iii) a Multivariate and Asymmetric Multivariate GARCH model with GJR extensions. The empirical results indicate that there is a high degree of volatility co-movement between Singapore stock market and that of Hong Kong, US, Japan and UK (in that order). Results support small but significant volatility spillover from Singapore into Hong Kong, Japan and US markets despite the latter three being dominant markets. Most of the previous research concludes that spillover effects are significant only from the dominant market to the smaller market and that the volatility spillover effects are unidirectional. Our study evinces that it is plausible for volatility to spill over from the smaller market to the dominant market. At a substantive level, studies on volatility co-movement and spillover provide useful information for risk analysis.
\end{abstract}

JEL Classification: C32, F3, G15

Key words: Volatility co-movement, volatility spillover, multivariate GARCH

\section{Acknowledgements:}

We are grateful to Dr Marcel Fratzscher of the European Central Bank for helping with the computer programs for the multivariate $\mathrm{GARCH}$ analysis and for his comments and suggestions.

\section{Correspondence to:}

${ }^{a}$ Lakshmi Bala , Department of Economics, National University of Singapore, 1 Arts Link, AS2, Singapore 117570. Email: artp1438@nus.edu.sg

${ }^{\mathbf{b}}$ Dr Gamini Premaratne, Department of Economics, National University of Singapore, AS2 Level 6, \#04-27A, 1 Arts Link, Singapore 117570. Email: gamini@nus.edu.sg 


\section{INTRODUCTION AND OVERVIEW}

Many researchers have studied the movements of aggregate stock market volatility. Generally, studies on volatility in US and Japanese stock markets tend to dominate the literature. However, the literature on volatility co-movement of stock markets is sparse. Comparatively little has been done on volatility co-movement between the Singapore stock market and that of North America, Europe and Asia. It is the limited nature and paucity of such work in existing literature that has spurred us to investigate the volatility co-movement of the Singapore market with major stock markets. Our choice of US, Hong Kong, Japan and UK stock markets is based on the criteria of leadership and influence that these markets have on the world economy. The US stock market is one of the world's most influential markets in the world. It is a market leader in the North American region. We select the UK stock market as it is the most influential in the European region while the stock markets of Hong Kong and Japan are the most vibrant and robust markets in the Asian region.

The study of volatility in the Singapore stock market vis-à-vis major world markets is important for several reasons: Firstly, when asset prices in Singapore fluctuate sharply over timedifferentials as short as a couple of days due to what is happening in other markets, it is hard to attribute these differentials to fundamental economic factors. This may lead to an erosion of confidence in our capital markets and a reduced flow of capital into Singapore's equity markets. Secondly, volatility is synonymous with risk and so increased risk associated with a given economic activity should, therefore, see a reduced level of participation in that activity. As such, when the Singapore stock market exhibits high volatility, a reduced level of participation can be expected. This can have adverse consequences for investment in Singapore. Singapore Exchange's (SGX) market capitalization accounts for 392.3 billion dollars (as of 1 November 2002). The following quote encapsulates how stock market volatility has implications on financial and economic activities in Singapore and the dynamics of major stock markets around the world can have ramifications on the Singapore stock market.

"It's the firmer share prices that contributed to the rise in market capitalisation as there were no large share issues in the market in October said Mr Seah Hiang Hong, Research Head at Kim Eng Ong Asia Securities "' - Source: The Straits Times, 1 Nov 2002. 
"Improved third quarter corporate earnings in the United States and some bargain hunting were factors that led to the rally in the local bourse in the past three weeks" - Source: The Straits Times, 1 Nov 2002

The financial literature offers much research on stock market volatility over time and linkages that exist among world markets. Eun and Shim (1989) analyzed daily stock market returns of Australia, Hong Kong, Japan, France, Canada, Switzerland, Germany, US and the UK. They found existence of substantial interdependence among the national stock markets with US being the most influential market. Against US innovations, all European and Asia-Pacific markets respond strongly with a one day lag. Most responses to a shock are completed within two days. Using daily and intraday price and stock returns data, Hamao, Masulis and $\mathrm{Ng}$ (1990) find that there are significant spillover effects from the US and the UK stock markets to the Japanese market but not the other way round. However, Lin, Engle and Ito (1994) find that foreign returns can significantly influence the domestic returns as in the case of Japan and US. This study finds that cross-market interdependence in returns and volatilities is bi-directional between the New York and Tokyo markets.

Park and Fatemi (1993) examine the linkages between the equity markets of the PacificBasin countries to those of the US, UK and Japan. The US market is the most influential compared to that of UK and Japan. It was found that Australia is most sensitive to the US market. Singapore, Hong Kong and New Zealand form the next group and exhibit moderate linkages. Korea, Taiwan and Thailand exhibit little linkage to any of these markets. Pacific-Basin economies have unique structures different from those of developed markets and its stock movements are influenced by domestic factors. Janakiramanan and Lamba (1998) empirically examine the linkages between the Pacific-Basin stock markets. Results show that the US influences all other markets, except for relatively isolated market of Indonesia. Markets that are geographically and economically close and/or have large number of cross-border listings exert significant influence over each other. Overall, the influence of the US market on the Australasian markets has diminished over more recent years, and the emerging market of Indonesia is becoming more integrated with these markets.

$\mathrm{Ng}$ (2000) examines the magnitude and changing nature of volatility spillovers from Japan and the US to six Pacific-Basin equity markets. The study finds that regional and world 
factors are important for market volatility in the Pacific-Basin region, though world market influence tends to be greater. The importance of the regional and world markets is influenced by important liberalization events. The proportion of Pacific-basin market volatility captured by the regional and world factors is small. In four out of six Pacific-Basin countries, Japanese and US shocks together account for less than $10 \%$ of weekly variation in returns. However, Johnson and Soenen (2002) investigate to what degree equity markets in Asia are integrated with Japan's equity market. They find that the equity markets of Australia, China, Hong Kong, Malaysia, New Zealand, and Singapore are highly integrated with the stock market in Japan. There is also evidence that the Asian markets became more integrated over time, especially since 1994.

A lot of work has been done on market linkages, market integration, influences and spillovers of one market on another. What the literature lacks are studies on stock market volatility co-movement and volatility spillovers with a focus on the Singapore market vis-à-vis world markets. This academic exercise serves to fill that gap and to contribute to this area by examining volatility, volatility co-movement and volatility spillovers between the Singapore stock market and the four major markets. We address the following three research questions

1. What is the degree and nature of volatility co-movement between the Singapore stock market with that of Hong Kong, Japan, US and UK?

2. How much of the movements in the Singapore stock market can be explained by movements and innovations/shocks in the US, Japan, Hong Kong and UK stock markets?

3. What is the nature of volatility spillover between the Singapore stock market and that of Hong Kong, Japan, US and UK?

\section{SAMPLE AND STATISTICAL PROPERTIES}

Singapore Exchange (SGX) is Asia-Pacific's first demutualised and integrated securities

and derivatives exchange. SGX was inaugurated on 1 December 1999, following the merger of two established and well-respected financial institutions - the Stock Exchange of Singapore (SES) and the Singapore International Monetary Exchange (SIMEX). On 23 November 2000, SGX became the first exchange in Asia-Pacific to be listed via a public offer and a private placement. Listed on our bourse, our stock is a component of benchmark indices such as the MSCI Singapore 
Free Index and the Straits Times Index. Our study uses daily stock returns data. The daily returns $y_{t}$ data is computed using the Straits Times Index:

$$
y_{t}=\left(\ln P_{t}-\ln P_{t-1}\right) * 100
$$

The price data was obtained using Datastream. The sample period spans from January 1, 1992 to August 26, 2002. Daily returns data is able to capture all the possible interactions. Using weekly or monthly data may block out interactions that last for only a few days. Table 1 provides information on the opening and closing times of the various markets and the indices that are used in this study. The order in which the markets open for trading is: Japan, Singapore, Hong Kong, the UK and US. The operations timing of the SGX overlaps with the exchanges in Hong Kong and Japan. The overlapping of hours has implications for what happens in the Singapore market. Shocks that occur in the Japanese and Hong Kong stock markets affect the Singapore stock market on the very same day without any time lag while shocks from the US and UK markets do not overlap with the Singapore market. Hence shocks that take place in these markets will affect the Singapore market on the following day.

According to Janakiramanan \& Lamba (1998), when countries share geographical proximity and have similar groups of investors in their markets, these markets are more than likely to influence each other. The more dominant market is likely to exert greater influence on the relatively smaller market. We examine the time invariant unconditional correlation coefficients for the first moments for the stock markets that we are analyzing. From Table 2, it can be seen that all correlation coefficients are significant. Daily market returns of Singapore are highly correlated with that of Hong Kong. In fact, Singapore and Hong Kong show the highest correlation of 0.60. Following Hong Kong, the Singapore market returns is correlated with the 1 day lagged US market returns. A correlation of 0.34 is exhibited. This is also highly significant. The Japanese and the Singapore returns show significant correlation. However, it is not as high as that observed for US and Hong Kong. The Singapore stock market is least correlated with the UK market. We also analyze the movements of the STI over the last ten years and compare it movements in the DJIA, Hang Seng, Nikkei 225 and FTSE. Figure 1 shows the plot of the STI over the last 10 years. The top five largest price decreases in the SGX took place on the order of 14 April 2000, 27 October 
1997, 3 January 2000, 11 September 2001 and 7 January 1998. What is interesting to note is that the force behind these large price falls were not due to domestic factors was due to negative shocks and events taking place in other stock markets. Volatility in the world's major stock markets has reverberated to the Singapore stock market. The biggest fall in the STI on 14 April 2000 was due to the technology stock bubble burst in the US market. The STI fell by about $8.44 \%$. The second largest plunge in the STI took place on 27 October 1997. This was due to loss of investor confidence in Hong Kong. Investors in Hong Kong went on a selling spree and drove the Hang Seng down by about $10 \%$ and this had repercussions on the Singapore market. The plunge in the STI on 3 January 2000 was due to the re-opening of the stock market after the New Year as there was considerable fear about the outcome of the Y2K bug. However, the problem posed no threat and markets picked up the following day. The 11 September 2001 terrorist attacks in the US had a large impact on the STI. Price fell by about 116 points. The fifth largest price fall took place on 7 January 1998. The worsening of the Asian currency crisis and the failure of a high-flying Hong Kong investment bank induced a breath taking plunge in local share prices.

Figure 2 shows a plot of stock price indices and returns of Singapore, Hong Kong, Japan, US and UK over the last 10 years. The movement of US and UK stock price indices shows similar trends and pattern while that of Hong Kong and Singapore are similar. Japan's stock price index exhibits a downward trend. All indices consistently show a dip in 1998.

Table 3 provides some statistical properties of daily market returns for the five countries. Hong Kong exhibits the highest standard deviation followed by, Japan, Singapore, UK and US. All five countries have distributions with positive excess kurtosis and are seen to have heavy tails. If the kurtosis exceeds 3 , the distribution is said to be leptokurtic relative to the normal. This implies that the distribution of stock returns in these countries tend to contain extreme values. The Jarque-Bera is a test statistic for testing whether the series is normally distributed. According to the test, normality is rejected for all the returns series for all five countries. It can be said that the Singapore stock market shows the most extreme values for the daily market returns compared to Hong Kong, US, UK and Japan. This indicates that volatility is much higher in the Singapore market compared to the rest. Singapore exhibits the lowest positive mean returns of 0.01 compared to that of US, Hong Kong and UK. The Japanese stock market shows negative mean 
returns of -0.03 . The difference between the maximum and minimum returns for the Singapore market (14.87 to -9.67) is much higher compared to US, UK and Japan. This implies that the Singapore stock market undergoes large fluctuations compared to Hong Kong. This is not surprising considering the relative smallness and openness of the stock market and vulnerability to global shocks. Singapore and Hong Kong show the largest standard deviations in returns. Singapore's standard deviation is 1.37 while that of Hong Kong is 1.77. Singapore's standard deviation is higher than that observed for US (1.00) and the UK (1.04). This shows that the Singapore market exhibits high fluctuations from the mean returns.

\section{THE ECONOMETRIC MODELS}

Volatility is associated with unpredictability, uncertainty and has implications for variance risk. Generally, people tend to see volatility as a symptom of market disruption whereby securities are not being priced fairly and the capital market is not functioning as well as it should. As mentioned earlier in the introduction, changes in the volatility of stock market returns are capable of having significant negative effects on risk averse investors and the economy. In the context of Singapore, increased volatility in our domestic stock market can impact consumption patterns, corporate capital investment decisions, leverage decisions, the business cycle and macroeconomic variables. With volatility being contagious, it is crucial for us to know what takes

place in the four major markets and how volatility in the Singapore stock market co-moves with that of the four markets. Such volatility co-movement can impact corporate capital budgeting decisions, investor's decisions and business cycle variables in Singapore. Our estimation of volatility co-movements in the Singapore, Hong Kong, US , Japan and UK markets is based using a (i) univariate GARCH model, (ii) Asymmetric GARCH models and a (iii) multivariate GARCH model with asymmetric extensions .

\subsection{The Univariate GARCH Model and Asymmetry Extensions}

The most important development in modeling volatility changes was the ARCH model, introduced by Engle (1982). Engle's insight was to set the conditional values of a series of errors, $\varepsilon_{t}{ }^{\prime} s$, as a function of lagged errors, time $(\mathrm{t})$, parameters, and predetermined variables: 


$$
\begin{aligned}
& \sigma_{t}^{2}=\sigma^{2}\left(\varepsilon_{t-1}, \varepsilon_{t-2}, \ldots \ldots \ldots, t, \xi, x_{t}\right) \\
& \varepsilon_{t}=\sigma_{t} Z_{t}
\end{aligned}
$$

where $Z_{t} \sim$ i.i.d with $\mathrm{E}\left(Z_{t}\right)=0$, and $\mathrm{E}\left(Z_{t}\right)=1$. By definition, $\varepsilon_{t}$ is serially uncorrelated and has zero mean. However, the conditional variance of $\varepsilon_{t}$ conditioned on all available information at time $t-1$ as given in (4) equals $\sigma_{t}^{2}$ :

$$
\sigma_{t}^{2}=\omega+\sum_{i=1}^{p} \alpha_{i} \varepsilon_{t-1}^{2}
$$

where $\omega$ and $\alpha_{i}$ 's are nonnegative constants (in order for $\sigma_{t}^{2}$ to be nonnegative). The ARCH model given by (4) is formulated to depict volatility as the clustering of large shocks to the dependent variable. Bollerslev (1986) extended the ARCH model into the GARCH i.e., Generalised $A R C H$. The innovation here is that GARCH allows past conditional variances to enter equations (4) and (5). The intention of GARCH is that it can parsimoniously represent a higher order ARCH process. The GARCH (p, q) can be represented as follows:

$$
\sigma_{t}^{2}=\omega+\sum_{i=1}^{p} \alpha_{i} \varepsilon_{t-i}^{2}+\sum_{j=1}^{q} \beta_{i} \sigma_{t-i}^{2}
$$

$\sigma_{t}^{2}$ is a function of lagged values of $\varepsilon_{t}^{2}$ and $\omega,\left\{\alpha_{i}\right\}, i=1 \ldots p$ and $\left\{\beta_{i}\right\}, j=1 \ldots q$ are nonnegative constants. The simplest of GARCH models can be expressed as in (5). For detailed discussion on ARCH models refer to survey papers by Bera and Higgins (1991) and Bollerslev, Chou and Kroner (1992)

$$
\begin{aligned}
& \varepsilon_{t}^{2}=\omega+\sum_{i=1}^{p}\left(\alpha_{i}+\beta_{i}\right) \varepsilon_{t-i}^{2}-\sum_{i=1}^{p} \beta_{i}\left[\varepsilon_{t-i}^{2}-\sigma_{t-i}^{2}\right]+\left[\varepsilon_{t}^{2}-\sigma_{t-i}^{2}\right] \\
& \sigma_{t}^{2}=\omega+\alpha \varepsilon_{t-1}^{2}+\beta \sigma_{t-1}^{2}=\frac{\omega}{(1-\beta)}+\alpha \sum_{i=0}^{\infty} \beta^{i} \varepsilon_{t-i-1}^{2}
\end{aligned}
$$

Nelson's (1991) EGARCH represents a more successful attempt to model excess conditional kurtosis in stock return indices based on a generalized exponential distribution. Nelson (1991) was the first investigator to model leverage effects, That is, the down movements are more 
influential for predicting volatility that the upward movements. The exponential EGARCH model can be represented as follows:

$$
\log \sigma_{t}^{2}=\omega+\sum_{i=1}^{p} \beta_{i} \log \sigma_{t-i}^{2}+\sum_{i=1}^{p} \alpha_{i} \frac{\left|\varepsilon_{t-i}\right|}{\sigma_{t-i}}+\sum_{i=1}^{p} \gamma_{i} \frac{\varepsilon_{t-i}}{\sigma_{t-i}}
$$

Equation (8) allows positive and negative values of $\varepsilon_{t}$ to have different impacts on volatility. The

EGARCH model is asymmetric because the level $\frac{\left|\varepsilon_{t-i}\right|}{\sigma_{t-i}}$ is included with coefficient $\gamma_{i}$. Since this coefficient is typically negative, positive return shocks generate less volatility than negative return shocks, ceteris paribus.

The GJR model or Threshold ARCH was introduced independently by Zakoian (1990) and Glosten, Jaganathan, and Runkle (1993). The specification for the conditional variance is given by (here we specifiy a TGARCH version):

$$
\sigma_{t}^{2}=\omega+\sum_{i=1}^{q} \alpha_{i} \varepsilon_{t-i}^{2}+\gamma \varepsilon_{t-1}^{2} d_{t-1}+\sum_{i=1}^{p} \beta_{i} \sigma_{t-i}^{2}
$$

where $d_{t}=1$ if $\varepsilon_{t}<0$, and 0 otherwise. In this model, good news $\left(\varepsilon_{t}>0\right)$, and bad news $\left(\varepsilon_{t}<0\right)$, have differential effects on the conditional variance- good news has an impact of $\alpha$, while bad news has an impact of $(\alpha+\gamma)$. If $\gamma>0$ we say that the leverage effect exists. If $\gamma \neq 0$, the news impact is asymmetric. Hence it can be seen that markets are more volatile when there is bad or negative news.

\subsection{The Vector Autoregression Model}

It has been widely recognized that inter-relationships exist among major financial stock markets. If we want to study the co-movement of volatility of stock markets, it is imperative that we also analyze the market dynamics, transmission and propagation mechanism driving these stock markets. We need to understand how shocks and volatility in one market is transmitted to other markets in a clearly recognizable fashion. For that we need to look at the extent to which multi-lateral interaction exists between these markets. For this to be possible, attention has to be paid to the structure of interdependence among the stock markets that is being analyzed. Once this structure of interdependence is ascertained, one can go on to study a group of stock markets as a 
system. Upon identifying the channels of interaction we can see the implications for co-movement of volatility. For this purpose, we use the VAR model.

The VAR model was developed by Sims (1980) with the purpose of estimating unrestricted reduced-form equations that have uniform sets of lagged dependent variables as regressors. The VAR model thus estimates a dynamic simultaneous equation system, free of $a$ priori restrictions on the structure of relationships. Since no restrictions are imposed on the structural relationships between variables, the VAR system can be a flexible approximation to the reduced form of the correctly specified but unknown model of the actual economic structure. As structural models tend to be misspecified, VAR can be used for the purpose of stylizing empirical regularities among time series data.

In this study, the VAR model is expressed as:

$$
Z(t)=C+\sum_{s=1}^{m} A(s) Z(t-s)+e(t)
$$

where $Z(t)$ is a $5 \times 1$ column vector of rates of return of five stock markets, $C$ is the deterministic component comprised of a constant, $A(s)$ are respectively , $5 \times 1$ and $5 \times 5$ matrices of coefficients, $m$ is the lag length, and $e(t)$ is the $5 \times 1$ innovation vector. By construction, $e(t)$ is uncorrelated with all the past $Z(s)$. The estimated VAR can be inverted to form the moving average representation of the system expressed as:

$$
Z(t)=\sum_{s=0}^{k} B(s) e(t-s)
$$

where $Z(t)$ is a linear combination of current an past one-step-ahead forecast errors or innovations. The $i, j t h$ component of $B(s)$ shows the response of the $i$ th market in s periods after a unit random shock in the $j$ th market. The $e(t)$ s are serially uncorrelated by construction, although they may be contemporaneously correlated.

In order to capture 'pure' responses, it is important to transfer the error terms. A lower triangular matrix $V$ is chosen to obtain the orthogonalized innovations $u$ from $e=V U$. The $i, j t h$ component of $B(s) V$ in equation (12) represents the impulse response of the $i$ th market in the $s$ periods to a shock of one standard error in the $j$ th market: 


$$
Z(t)=\sum_{s=0}^{k} B(s)-V u(t-s)
$$

The orthogonalization also provides $\sum C_{i j}^{2}(s)$, which is the component of forecast error variance in the $t+1$-step ahead forecast of $Z_{i}$ that is accounted for innovation in $Z_{j}$. This decomposition of the forecast error variance gives a measure of how important one variable is in generating fluctuations in its own and other variables. The Monte Carlo option is selected to infer the distribution of the matrix of impulse response coefficients. As impulse responses are highly non-linear functions of the estimated parameters, Monte Carlo integration techniques are recommended to calculate the confidence bands. Refer to Soydemir (2000).

\subsection{The Multivariate GARCH Model and GJR Extensions}

The ultimate analysis of volatility co-movement has to be done using a systemic approach, i.e., analyzing volatility in the five markets as a whole system. In order to capture the co-movement of volatility between Singapore, Hong Kong, US, Japan and UK; we estimate a multivariate GARCH model. A multivariate GARCH model helps to capture the dynamic relationship between Singapore and the four stock markets. Modelling the volatility of the five markets simultaneously has several advantages over the univariate approach that has been used so far. As highlighted by Koutmous and Booth (1995), first, a multivariate approach eliminates the two-step procedure, thereby avoiding problems associated with estimated regressors. Second, it improves the efficiency and the power of the tests for cross market co-movement and spillovers. Third, it is methodologically consistent with the notion that volatility spillovers are manifestations of the impact of global shocks on any given market.

Inferences about the magnitude of volatility shocks that originate in any one of the markets and that transmit to other markets, especially Singapore, depend on how cross-market dynamics are modelled. We use a multivariate $\operatorname{GARCH}(1,1)$ model with information variables and constant conditional correlation. The GARCH model is estimated by computing the conditional log-likelihood function

$$
L(\Theta)=-\left(\frac{T}{2}\right) \ln (2 \pi)-\frac{1}{2} \sum_{t=1}^{T}\left(\ln \left|\sigma_{t}\right|+\varepsilon_{t}^{\prime} \sigma_{t}^{-1} \varepsilon_{t}\right)
$$


where $\Theta$ is the parameter vector to be estimated, $T$ the number of observations and $\sigma_{t}$ the time varying conditional variance-covariance matrix. The Simplex algorithm is used to get initial values for the maximization problem. To obtain the parameter estimates, the numerical maximization is used adopted through the algorithm developed by Berndt, Hall, Hall and Hausman (1974).

The spillovers of the other four volatilities are included as either contemporaneous or lagged squared innovations depending on whether the operating hours of the five stock markets are synchronous. As the US and UK markets open and close after the Singapore, Hong Kong and Japanese markets, the North American and European markets affect the Asian markets the following day. Innovations in the Hong Kong and Japanese stock markets should affect the Singapore market on the same day due to overlapping operating hours. However, the multivariate approach requires the modelling of volatility in the five markets simultaneously. By setting the squared innovations of Hong Kong and Japan to be contemporaneous, there lies the problem of simultaneity bias in the variance equations. Moreover, if we were to include Singapore, Hong Kong and Japan both as contemporaneous squared external innovations in the variance equations of each other, there is then the problem of over-identification, i.e. either Singapore shocks affect the Hong Kong and Japanese markets contemporaneously or vice-versa but the three markets cannot be affecting each other contemporaneously. In order to overcome this problem, we include volatility shocks as being contemporaneous, in one of the three markets and the other two as lagged. We then switch the lags in the variance equations of Singapore, Hong Kong and Japan. In order to overcome this problem, we stipulate three different lag structures (i.e. Cases 1, 2 and 3) that more or less captures all plausible volatility interactions.

The conditional first moments of the multivariate GARCH model in vector format are estimated as:

$$
y_{j, t}=\left[\begin{array}{l}
y_{S G, t} \\
y_{H K, t} \\
y_{U S, t} \\
y_{J P, t} \\
y_{U K, t}
\end{array}\right]=\left[\begin{array}{l}
\mu_{S G, t-1} \\
\mu_{H K, t-1} \\
\mu_{U S, t-1} \\
\mu_{J P, t-1} \\
\mu_{U K, t-1}
\end{array}\right]+\left[\begin{array}{l}
\varepsilon_{S G, t} \\
\varepsilon_{H K, t} \\
\varepsilon_{U S, t} \\
\varepsilon_{J P, t} \\
\varepsilon_{U K, t}
\end{array}\right]
$$


where $y_{j, t}$ is a $5 \times 1$ vector of excess returns. It consists of the predictable part $\mu_{j, t}$ and an unpredictable part, $\varepsilon_{t}$. The vector of innovations, $\varepsilon_{t}$, is assumed to be normally distributed conditional on the past information set, $\Omega_{t-1}$, that is $\varepsilon_{j, t} \mid \Omega_{t-1} \sim N\left(0, \sigma_{\varepsilon, j, t}^{2}\right)$. The assumption of conditionally normal distributed innovations does not contradict the empirical evidence of excess kurtosis in the unconditional returns. Conditional normal distributed innovations can also produce excess kurtosis in the unconditional returns when volatility exhibits some persistence. The unconditional returns of Singapore, Hong Kong, US, Japan and UK are leptokurtic relative to the normal. From the univariate analysis, volatility in the five stock markets does exhibit persistence. Due to conditional heteroskedasticity in the idiosyncratic innovations $\varepsilon_{j, t}$ with $\varepsilon_{j, t} \mid \Omega_{j, t-1} \sim N\left(0, \sigma_{\varepsilon, j, t}^{2}\right)$ the $5 \times 1$ vector of conditional variance of $\varepsilon_{j, t}$ is modelled as equation (15).

From (15), it can be seen that the conditional variance is determined by its own past variance, own past squared shock and by lagged squared external innovations. The $\alpha{ }_{A-B}$ coefficient measures the spillover effects of volatility from country B to country A. For example, $\alpha_{S G-H K}$ measures the volatility spillover from the Hong Kong market to the Singapore market. We must emphasize that the volatility spillover coefficient $\alpha_{A-B}$ is also a reflection of the degree of volatility co-movement between the markets. Statistically significant spillover coefficients imply that significant volatility shocks are imported from market B into market A through the variances. As volatility spillover from market $\mathrm{B}$ to market A becomes more pronounced, volatility co-movement between the two markets increases. This is because, with increased volatility spillover into market A, volatility of market A tends to be similar to volatility in market B and this leads to greater co-movement. 


$$
\begin{aligned}
\sigma_{\varepsilon, j, t}^{2}= & {\left[\begin{array}{l}
\sigma_{\varepsilon, S G, t}^{2} \\
\sigma_{\varepsilon, H K, t}^{2} \\
\sigma_{\varepsilon, U S, t}^{2} \\
\sigma_{\varepsilon, J P, t}^{2} \\
\sigma_{\varepsilon, U K, t}^{2}
\end{array}\right]=\left[\begin{array}{l}
\omega_{S G, 0} \\
\omega_{H K, 0} \\
\omega_{U S, 0} \\
\omega_{J P, 0} \\
\omega_{U K, 0}
\end{array}\right]+\left[\begin{array}{c}
\beta_{S G} \sigma_{\varepsilon, S G, t-1}^{2} \\
\beta_{H K} \sigma_{\varepsilon, H K, t-1}^{2} \\
\beta_{U S} \sigma_{\varepsilon, U S, t-1}^{2} \\
\beta_{J P} \sigma_{\varepsilon, J P, t-1}^{2} \\
\beta_{U K} \sigma_{\varepsilon, U K, t-1}^{2}
\end{array}\right]+\left[\begin{array}{l}
\alpha_{S G-S G} \varepsilon_{S G, t-1}^{2} \\
\alpha_{H K-H K} \varepsilon_{H K, t-1}^{2} \\
\alpha_{U S-U S} \varepsilon_{U S, t-1}^{2} \\
\alpha_{J P-J P} \varepsilon_{J P, t-1}^{2} \\
\alpha_{U K-U K} \varepsilon_{U K, t-1}^{2}
\end{array}\right] } \\
& +\left[\begin{array}{lllll}
0 & \alpha_{S G-H K} & \alpha_{S G-U S} & \alpha_{S G-J P} & \alpha_{S G-U K} \\
\alpha_{H K-S G} & 0 & \alpha_{H K-U S} & \alpha_{H K-J P} & \alpha_{H K-U K} \\
\alpha_{U S-S G} & \alpha_{U S-H K} & 0 & \alpha_{U S-J P} & \alpha_{U S-U K} \\
\alpha_{J P-S G} & \alpha_{J P-H K} & \alpha_{J P-U S} & 0 & \alpha_{J P-U K} \\
\alpha_{U K-S G} & \alpha_{U K-H K} & \alpha_{U K-U S} & \alpha_{U K-J P} & 0
\end{array}\right]\left[\begin{array}{l}
\varepsilon_{S G, t}^{2} \\
\varepsilon_{H K, t}^{2} \\
\varepsilon_{U S, t-1}^{2} \\
\varepsilon_{J P, t}^{2} \\
\varepsilon_{U K, t-1}^{2}
\end{array}\right]
\end{aligned}
$$

\section{Variance equations for Case 1:}

$$
\begin{aligned}
& \sigma_{\varepsilon, S G, t}^{2}=\omega+\beta_{S G} \sigma_{t-1}^{2}+\alpha_{S G} \varepsilon_{t-1}^{2}+\alpha_{S G-H K} \varepsilon_{H K, t-1}^{2}+\alpha_{S G-U S} \varepsilon_{U S, t-1}^{2}+\alpha_{S G-J P} \varepsilon_{J P, t-1}^{2}+\alpha_{S G-U K} \varepsilon_{U K, t-1}^{2} \\
& \sigma_{\varepsilon, H K, t}^{2}=\omega+\beta_{H K} \sigma_{t-1}^{2}+\alpha_{H K} \varepsilon_{t-1}^{2}+\alpha_{H K-S G} \varepsilon_{S G, t}^{2}+\alpha_{H K-U S} \varepsilon_{U S, t-1}^{2}+\alpha_{H K-J P} \varepsilon_{J P, t}^{2}+\alpha_{H K-U K} \varepsilon_{U K, t-1}^{2} \\
& \sigma_{\varepsilon, U S, t}^{2}=\omega+\beta_{U S} \sigma_{t-1}^{2}+\alpha_{U S} \varepsilon_{t-1}^{2}+\alpha_{U S-S G} \varepsilon_{S G, t}^{2}+\alpha_{U S-H K} \varepsilon_{H K, t}^{2}+\alpha_{U S-J P} \varepsilon_{J P, t-1}^{2}+\alpha_{U S-U K} \varepsilon_{U K, t}^{2} \\
& \sigma_{\varepsilon, J P, t}^{2}=\omega+\beta_{J P} \sigma_{t-1}^{2}+\alpha_{J P} \varepsilon_{t-1}^{2}+\alpha_{J P-S G} \varepsilon_{S G, t}^{2}+\alpha_{J P-H K} \varepsilon_{H K, t-1}^{2}+\alpha_{J P-U S} \varepsilon_{U S, t}^{2}+\alpha_{J P-U K} \varepsilon_{U K, t-1}^{2} \\
& \sigma_{\varepsilon, U K, t}^{2}=\omega+\beta_{U K} \sigma_{t-1}^{2}+\alpha_{U K} \varepsilon_{t-1}^{2}+\alpha_{U K-S G} \varepsilon_{S G, t}^{2}+\alpha_{U K-H K} \varepsilon_{H K, t}^{2}+\alpha_{U K-U S} \varepsilon_{U S, t-1}^{2}+\alpha_{U K-J P} \varepsilon_{J P, t}^{2}
\end{aligned}
$$

\section{Variance equations for Case 2:}

$$
\begin{aligned}
& \sigma_{\varepsilon, S G, t}^{2}=\omega+\beta_{S G} \sigma_{t-1}^{2}+\alpha_{S G} \varepsilon_{t-1}^{2}+\alpha_{S G-H K} \varepsilon_{H K, t}^{2}+\alpha_{S G-U S} \varepsilon_{U S, t}^{2}+\alpha_{S G-J P} \varepsilon_{J P, t}^{2}+\alpha_{S G-U K} \varepsilon_{U K, t}^{2} \\
& \sigma_{\varepsilon, H K, t}^{2}=\omega+\beta_{H K} \sigma_{t-1}^{2}+\alpha_{H K} \varepsilon_{t-1}^{2}+\alpha_{H K-S G} \varepsilon_{S G, t-1}^{2}+\alpha_{H K-U S} \varepsilon_{U S, t}^{2}+\alpha_{H K-J P} \varepsilon_{J P, t-1}^{2}+\alpha_{H K-U K} \varepsilon_{U K, t}^{2} \\
& \sigma_{\varepsilon, U S, t}^{2}=\omega+\beta_{U S} \sigma_{t-1}^{2}+\alpha_{U S} \varepsilon_{t-1}^{2}+\alpha_{U S-S G} \varepsilon_{S G, t-1}^{2}+\alpha_{U S-H K} \varepsilon_{H K, t-1}^{2}+\alpha_{U S-J P} \varepsilon_{J P, t}^{2}+\alpha_{U S-U K} \varepsilon_{U K, t-1}^{2} \\
& \sigma_{\varepsilon, J P, t}^{2}=\omega+\beta_{J P} \sigma_{t-1}^{2}+\alpha_{J P} \varepsilon_{t-1}^{2}+\alpha_{J P-S G} \varepsilon_{S G, t-1}^{2}+\alpha_{J P-H K} \varepsilon_{H K, t}^{2}+\alpha_{J P-U S} \varepsilon_{U S, t-1}^{2}+\alpha_{J P-U K} \varepsilon_{U K, t}^{2} \\
& \sigma_{\varepsilon, U K, t}^{2}=\omega+\beta_{U K} \sigma_{t-1}^{2}+\alpha_{U K} \varepsilon_{t-1}^{2}+\alpha_{U K-S G} \varepsilon_{S G, t-1}^{2}+\alpha_{U K-H K} \varepsilon_{H K, t-1}^{2}+\alpha_{U K-U S} \varepsilon_{U S, t}^{2}+\alpha_{U K-J P} \varepsilon_{J P, t-1}^{2}
\end{aligned}
$$

\section{Variance equations for Case 3:}

$\sigma_{\varepsilon, S G, t}^{2}=\omega+\beta_{S G} \sigma_{t-1}^{2}+\alpha_{S G} \varepsilon_{t-1}^{2}+\alpha_{S G-H K} \varepsilon_{H K, t-1}^{2}+\alpha_{S G-U S} \varepsilon_{U S, t-1}^{2}+\alpha_{S G-J P} \varepsilon_{J P, t}^{2}+\alpha_{S G-U K} \varepsilon_{U K, t-1}^{2}$

$\sigma_{\varepsilon, H K, t}^{2}=\omega+\beta_{H K} \sigma_{t-1}^{2}+\alpha_{H K} \varepsilon_{t-1}^{2}+\alpha_{H K-S G} \varepsilon_{S G, t-1}^{2}+\alpha_{H K-U S} \varepsilon_{U S, t-1}^{2}+\alpha_{H K-J P} \varepsilon_{J P, t}^{2}+\alpha_{H K-U K} \varepsilon_{U K, t-1}^{2}$

$\sigma_{\varepsilon, U S, t}^{2}=\omega+\beta_{U S} \sigma_{t-1}^{2}+\alpha_{U S} \varepsilon_{t-1}^{2}+\alpha_{U S-S G} \varepsilon_{S G, t-1}^{2}+\alpha_{U S-H K} \varepsilon_{H K, t-1}^{2}+\alpha_{U S-J P} \varepsilon_{J P, t}^{2}+\alpha_{U S-U K} \varepsilon_{U K, t}^{2}$

$\sigma_{\varepsilon, J P, t}^{2}=\omega+\beta_{J P} \sigma_{t-1}^{2}+\alpha_{J P} \varepsilon_{t-1}^{2}+\alpha_{J P-S G} \varepsilon_{S G, t-1}^{2}+\alpha_{J P-H K} \varepsilon_{H K, t-1}^{2}+\alpha_{J P-U S} \varepsilon_{U S, t-1}^{2}+\alpha_{J P-U K} \varepsilon_{U K, t-1}^{2}$

$\sigma_{\varepsilon, U K, t}^{2}=\omega+\beta_{U K} \sigma_{t-1}^{2}+\alpha_{U K} \varepsilon_{t-1}^{2}+\alpha_{U K-S G} \varepsilon_{S G, t-1}^{2}+\alpha_{U K-H K} \varepsilon_{H K, t-1}^{2}+\alpha_{U K-U S} \varepsilon_{U S, t-1}^{2}+\alpha_{U K-J P} \varepsilon_{J P, t}^{2}$ 
Asymmetric multivariate GARCH model:

$\sigma_{\varepsilon, j, t}^{2}=\left[\begin{array}{l}\sigma_{\varepsilon, S G, t}^{2} \\ \sigma_{\varepsilon, H K, t}^{2} \\ \sigma_{\varepsilon, U S, t}^{2} \\ \sigma_{\varepsilon, J P, t}^{2} \\ \sigma_{\varepsilon, U K, t}^{2}\end{array}\right]=\left[\begin{array}{l}\omega_{S G, 0} \\ \omega_{H K, 0} \\ \omega_{U S, 0} \\ \omega_{J P, 0} \\ \omega_{U K, 0}\end{array}\right]+\left[\begin{array}{c}\beta_{S G} \sigma_{\varepsilon, S G, t-1}^{2} \\ \beta_{H K} \sigma_{\varepsilon, H K, t-1}^{2} \\ \beta_{U S} \sigma_{\varepsilon, U S, t-1}^{2} \\ \beta_{J P} \sigma_{\varepsilon, J P, t-1}^{2} \\ \beta_{U K} \sigma_{\varepsilon, U K, t-1}^{2}\end{array}\right]+\left[\begin{array}{l}\alpha_{S G-S G} \varepsilon_{S G, t-1}^{2} \\ \alpha_{H K-H K} \varepsilon_{H K, t-1}^{2} \\ \alpha_{U S-U S} \varepsilon_{U S, t-1}^{2} \\ \alpha_{J P-J P} \varepsilon_{J P, t-1}^{2} \\ \alpha_{U K-U K} \varepsilon_{U K, t-1}^{2}\end{array}\right]$

$+\left[\begin{array}{ccccc}0 & \alpha_{S G-H K} & \alpha_{S G-U S} & \alpha_{S G-J P} & \alpha_{S G-U K} \\ \alpha_{H K-S G} & 0 & \alpha_{H K-U S} & \alpha_{H K-J P} & \alpha_{H K-U K} \\ \alpha_{U S-S G} & \alpha_{U S-H K} & 0 & \alpha_{U S-J P} & \alpha_{U S-U K} \\ \alpha_{J P-S G} & \alpha_{J P-H K} & \alpha_{J P-U S} & 0 & \alpha_{J P-U K} \\ \alpha_{U K-S G} & \alpha_{U K-H K} & \alpha_{U K-U S} & \alpha_{U K-J P} & 0\end{array}\right]\left[\begin{array}{l}\varepsilon_{S G, t}^{2} \\ \varepsilon_{H K, t}^{2} \\ \varepsilon_{U S, t-1}^{2} \\ \varepsilon_{J P, t}^{2} \\ \varepsilon_{U K, t-1}^{2}\end{array}\right]$

$+\left[\begin{array}{ccccc}0 & \phi_{S G-H K} & \phi_{S G-U S} & \phi_{S G-J P} & \phi_{S G-U K} \\ \phi_{H K-S G} & 0 & \phi_{H K-U S} & \phi_{H K-J P} & \phi_{H K-U K} \\ \phi_{U S-S G} & \phi_{U S-H K} & 0 & \phi_{U S-J P} & \phi_{U S-U K} \\ \phi_{J P-S G} & \phi_{J P-H K} & \phi_{J P-U S} & 0 & \phi_{J P-U K} \\ \phi_{U K-S G} & \phi_{U K-H K} & \phi_{U K-U S} & \phi_{U K-J P} & 0\end{array}\right]\left[\begin{array}{l}A_{S G} \varepsilon_{S G, t}^{2} \\ A_{S G} \varepsilon_{H K, t}^{2} \\ A_{S G} \varepsilon_{U S, t-1}^{2} \\ A_{S G} \varepsilon_{J P, t}^{2} \\ A_{S G} \varepsilon_{U K, t-1}^{2}\end{array}\right]$

$+\left[\begin{array}{ccccc}0 & \eta_{S G-H K} & \eta_{S G-U S} & \eta_{S G-J P} & \eta_{S G-U K} \\ \eta_{H K-S G} & 0 & \eta_{H K-U S} & \eta_{H K-J P} & \eta_{H K-U K} \\ \eta_{U S-S G} & \eta_{U S-H K} & 0 & \eta_{U S-J P} & \eta_{U S-U K} \\ \eta_{J P-S G} & \eta_{J P-H K} & \eta_{J P-U S} & 0 & \eta_{J P-U K} \\ \eta_{U K-S G} & \eta_{U K-H K} & \eta_{U K-U S} & \eta_{U K-J P} & 0\end{array}\right]\left[\begin{array}{l}B_{S G} \varepsilon_{S G, t}^{2} \\ B_{S G} \varepsilon_{H K, t}^{2} \\ B_{S G} \varepsilon_{U S, t-1}^{2} \\ B_{S G} \varepsilon_{J P, t}^{2} \\ B_{S G} \varepsilon_{U K, t-1}^{2}\end{array}\right]$

$+\left[\begin{array}{ccccc}0 & \gamma_{S G-H K} & \gamma_{S G-U S} & \gamma_{S G-J P} & \gamma_{S G-U K} \\ \gamma_{H K-S G} & 0 & \gamma_{H K-U S} & \gamma_{H K-J P} & \gamma_{H K-U K} \\ \gamma_{U S-S G} & \gamma_{U S-H K} & 0 & \gamma_{U S-J P} & \gamma_{U S-U K} \\ \gamma_{J P-S G} & \gamma_{J P-H K} & \gamma_{J P-U S} & 0 & \gamma_{J P-U K} \\ \gamma_{U K-S G} & \gamma_{U K-H K} & \gamma_{U K-U S} & \gamma_{U K-J P} & 0\end{array}\right]\left[\begin{array}{l}C_{S G} \varepsilon_{S G, t}^{2} \\ C_{S G} \varepsilon_{H K, t}^{2} \\ C_{S G} \varepsilon_{U S, t-1}^{2} \\ C_{S G} \varepsilon_{J P, t}^{2} \\ C_{S G} \varepsilon_{U K, t-1}^{2}\end{array}\right]$

$+\left[\begin{array}{ccccc}0 & \lambda_{S G-H K} & \lambda_{S G-U S} & \lambda_{S G-J P} & \lambda_{S G-U K} \\ \lambda_{H K-S G} & 0 & \lambda_{H K-U S} & \lambda_{H K-J P} & \lambda_{H K-U K} \\ \lambda_{U S-S G} & \lambda_{U S-H K} & 0 & \lambda_{U S-J P} & \lambda_{U S-U K} \\ \lambda_{J P-S G} & \lambda_{J P-H K} & \lambda_{J P-U S} & 0 & \lambda_{J P-U K} \\ \lambda_{U K-S G} & \lambda_{U K-H K} & \lambda_{U K-U S} & \lambda_{U K-J P} & 0\end{array}\right]\left[\begin{array}{l}D_{S G} \varepsilon_{S G, t}^{2} \\ D_{S G} \varepsilon_{H K, t}^{2} \\ D_{S G} \varepsilon_{U S, t-1}^{2} \\ D_{S G} \varepsilon_{J P, t}^{2} \\ D_{S G} \varepsilon_{U K, t-1}^{2}\end{array}\right]$ 
In order to capture volatility asymmetry, we incorporate the GJR specification (Glosten , Jagannathan and Runkle , 1993). We extend the conditional variance equations to include an indicator function (or dummy variable). The dummy-variable set-up follows the approach of Fraztscher (2001). A , B, C and D are indicator functions (or dummy variables) that take on the value of 1 if the innovation is negative and value of 0 is the shock is positive. The parameter estimates for the asymmetric multivariate GARCH model is given by:

$$
\begin{gathered}
\sigma_{\varepsilon, j, t}^{2}=\omega+\beta_{j} \sigma_{t-1}^{2}+\alpha_{j} \varepsilon_{t-1}^{2}+\alpha_{a-b} \varepsilon_{b, t}^{2}+\alpha_{a-c} \varepsilon_{c, t-1}^{2}+\alpha_{a-d} \varepsilon_{d, t}^{2}+\alpha_{a-f} \varepsilon_{f, t-1}^{2} \\
+\phi_{a-b} A_{t} \varepsilon_{b, t}^{2}+\eta_{a-c} B_{t-1} \varepsilon_{c, t-1}^{2} \\
+\gamma_{a-d} C_{t} \varepsilon_{d, t}^{2}+\lambda_{a-f} D_{t-1} \varepsilon_{f, t-1}^{2}
\end{gathered}
$$

where $\mathrm{A}, \mathrm{B}, \mathrm{C}, \mathrm{D}=1$ if $\varepsilon_{t}<0$ or $\mathrm{A}, \mathrm{B}, \mathrm{C}, \mathrm{D}=0$ otherwise. $\phi, \eta, \gamma$ and $\lambda$ measure the impact of shocks. If the coefficients are significant, it implies that negative innovations have an asymmetric impact on volatility, i.e. downward movements in the market are followed by higher volatilities than upward movements of the same magnitude. In this model, positive shocks will have an impact of only $\alpha$ while negative shocks will have an impact of $(\alpha+\phi+\eta+\gamma+\lambda)$. (Here we are assuming that all coefficients representing asymmetry are significant). If $\phi, \eta, \gamma$ and $\lambda$ is greater than zero, we say that leverage effect exists. Equation (19) shows the set up for the asymmetric multivariate GARCH model. The GJR variations of Cases 1, 2 and 3 follows the general case indicated by (20).

\section{RESULTS}

\subsection{Results for Univariate GARCH Analysis and Asymmetric Extensions}

Table 4 report the parameter estimates from fitting an AR(p) model for Singapore, Hong Kong, Japan, US and the UK for the period 1992 to 2002. Table 5 reports the results of fitting GARCH $(1,1)$, EGARCH and GJR models. For the case of Singapore, the coefficients of the $\alpha_{1}, \beta_{1}$ and $\gamma_{1}$ are all significant. The $\gamma_{1}$ coefficient in the EGARCH model is negative. This implies that a positive returns shock to the Singapore stock market produces lower volatility than a negative returns shock. The $\gamma_{1}$ coefficient in the GJR model is 0.17 which is greater than 0 and is significant. This means that leverage effect exists in the Singapore stock market and news impact 
is asymmetric. The magnitude of the differential impact on conditional variance can be ascertained from the $\alpha$ and $\gamma$ values. Good news to the Singapore stock market has an impact of 0.07 while the impact of bad news on the conditional variance is given by $0.24(\alpha+\gamma)$. Volatility is seen to be persistent in the Singapore market. The sum of $\alpha_{1}$ and $\beta_{1}$ is very close to 1 . The half life is computed to be 69 days. Based on minimum AIC/SIC values and maximum log likelihood values, it can be concluded that the GJR model best captures volatility dynamics of the Singapore stock market. As for Hong Kong, the coefficients of the $\alpha_{1}, \beta_{1}$ and $\gamma_{1}$ are all significant. The $\gamma_{1}$ coefficient in the EGARCH model is negative. As in the case of Singapore, positive returns shock to the stock market produces lower volatility than a negative returns shock in the Hong Kong market. The $\gamma_{1}$ coefficient in the GJR model is 0.11 which is greater than 0 and is significant. This indicates the presence of leverage effect. Good news to the Hong Kong stock market has an impact of 0.02 while the impact of bad news on the conditional variance is given by 0.13 $(\alpha+\gamma)$. Volatility is also highly persistent in the Hong Kong market with a half life of 69 days. This is similar to that of the Singapore market. Just as in the case of Singapore, the GJR model best captures volatility dynamics of the Hong Kong market. As for Japan, the coefficients of the $\alpha_{1}, \beta_{1}$ and $\gamma_{1}$ are all significant. The $\gamma_{1}$ coefficient in the EGARCH model is -0.08 and is negative and significant. The $\gamma_{1}$ coefficient in the GJR model is 0.10 which is greater than 0 and is significant. This indicates the presence of leverage effect. Good news to the Japanese stock market has an impact of 0.02 while the impact of bad news on the conditional variance is given by $0.20(\alpha+\gamma)$. Volatility is not as persistent as it is in Hong Kong and Singapore. The half-life is 34 days. For Japan, the EGARCH model captures volatility dynamics well based on the lowest AIC/SIC values and highest maximum log likelihood values. In the case of US, the coefficients of the $\alpha_{1}, \beta_{1}$ and $\gamma_{1}$ are all significant except for $\alpha_{1}$ in the GJR model. The $\gamma_{1}$ coefficient in the EGARCH model is -0.09 and is negative and significant. The $\gamma_{1}$ coefficient in the GJR model is 0.11 which is greater than 0 and is significant. Leverage effect is supported. Good news to the US stock market has an impact of 0.01 while the impact of bad news on the conditional variance is given by $0.12(\alpha+\gamma)$. Volatility is as persistent it is in Hong Kong and Singapore. The half-life 
is 69 days. EGARCH best governs the dynamics of US stock market volatility. Lastly for UK, the coefficients of the $\alpha_{1}, \beta_{1}$ and $\gamma_{1}$ are all significant except for $\alpha_{1}$ in the GJR model. This is similar to US. The $\gamma_{1}$ coefficient in the EGARCH model is -0.07 and is negative and significant. The $\gamma_{1}$ coefficient in the GJR model is 0.13 which is greater than 0 and is significant. Leverage effect is supported as in the case of US. Good news to the UK stock market has an impact of 0.01 while the impact of bad news on the conditional variance is given by $0.14(\alpha+\gamma)$. Volatility is as persistent as it is in US. The half-life is 69 days. As in the case of Japan and US, the EGARCH model captures volatility dynamics of the UK market well.

On comparing the results and its implications for the Singapore market, we can see that Singapore exhibits comparatively higher $\alpha$ values than the other four economies in all three models. This implies that the effects of shocks in earlier periods tend to linger around for a longer period than it does in other stock markets. This may imply that the Singapore stock market shows less market efficiency than the other markets as the effects of the shocks take a longer time to dissipate. The $\beta_{1}$ parameters capture long term influences on volatility. What is interesting to note that all five markets exhibit very similar $\beta_{l}$ values. This shows that long term effects have similar influences on market volatility. In the EGARCH and GJR model, the $\gamma_{1}$ values show how good and bad news affects the volatility. Singapore's $\gamma_{1}$ value of (0.17) is comparatively higher than that exhibited by Hong Kong (0.11), Japan (0.10), US (0.11) and UK (0.13). This means that the leverage effect is higher in the Singapore stock market versus that experienced in the other markets. The impact of bad news and shocks has a much greater effect on Singapore. On the whole, it can be seen that the Singapore market is very vulnerable to external volatility movements in major markets, especially that of Hong Kong and US.

\subsection{Results for Vector Autoregression and Impulse Response Analyses}

In the estimation stage, unit root tests are run to analyze time-series properties of the price series. The results from the Augmented Dickey-Fuller test reveal that all the series are stationary in the form of first differences. Table 6, reports the results of the unit root test. The independent variables in the VAR model have to be lagged a certain number of times. The number of lags was 
chosen based on the Akaike-Schwarz Information Criteria. The Akaike and Schwarz tests suggest a lag order of two. Friedman and Shachmurove (1997) suggest that higher lag orders ensures that all the dynamics in the data is captured in analysis. Eun and Shim (1989) used 15 lags. However, in order to keep the model parsimonious, the Information Criteria will governed the lag length in this study.

Table 7 shows the parameter estimates obtained from fitting a VAR model. The parameter estimates between Singapore and the four other markets are found to be significant. After estimating a VAR model, we go on to obtain the variance decompositions. The decomposition of variance of the forecast errors of the returns of a given market indicates the relative importance of the various markets in causing the fluctuations in returns of that market. A leading market is one which explains a large percentage of the error variance of other markets while its own forecast error is not explained by innovations in other markets. Table 8 presents the decompositions of the forecast error variance for 5-day, 10-day and 15-day horizons. We begin by considering the effect of a shock that originates in the US and then moves to Japan, Hong Kong, Singapore and UK The markets have been ordered according to closing times. Entries show the percentage forecast error variance of the market in the first column explained by the market in the first row.

Table 8 shows that the US market accounts for between $6 \%$ and $21 \%$ of the forecast error variance of the other markets. The Hong Kong stock market accounts for approximately $22 \%$ of forecast error variances in the Singapore market followed by US which accounts for $12.41 \%$ of error variances of the Singapore market. Japan accounts for about $4.22 \%$ while UK has a $1 \%$ impact on Singapore's error variances. Singapore is the most endogenous market with almost $40 \%$ of its forecast error variance explained by the other markets in the system. This shows how open the Singapore stock market is and how vulnerable it is to shocks occurring in leading stock markets. Geographically and economically close countries like Singapore and Hong Kong show strong linkages. While Hong Kong exerts considerable influence of about $22 \%$ on the Singapore market, Singapore has hardly any impact on the Hong Kong market. Singapore accounts for only about $0.19 \%$ of forecast error variances of Hong Kong. 
Following the analysis on variance decomposition, we investigate the pattern of dynamic impulse response of Singapore to shocks in US, Japan, Hong Kong and the UK. The results provide insight on the efficiency of Singapore market with respect to the information contained in such shocks. The impulse response coefficients are normalized such that the unit is the standard deviation of the orthogonalized innovation. The initial shock in a variable is set equal to one standard error of innovation at $\mathrm{s}=0$. Despite different variations of returns across the equity markets considered, the normalized coefficients represent simulated impulse responses of Singapore to each of the four markets to a positive, one-standard deviation shock in the US, Japan, Hong Kong and the UK. Figure 3 shows the impulse response of Singapore to the other stock markets. When the lower band crosses the horizontal axis, the response becomes statistically insignificant.

The first panel of Figure 3 shows the response of the Singapore stock market to a shock in the US market. Singapore's peak response occurs on day two. There is a one day lag due to the time difference as US is one day behind. By day three, the impact of the shock becomes insignificant. The second panel shows the response to a shock in the Japanese market. Peak response occurs on the first day of the shock. The impact of the shock dies off by the second day. In the third panel, we see Singapore's response to a shock from the Hong Kong market. Peak response occurs on day one. What is interesting to note is that Singapore's response to a Hong Kong shock is persistent. The impact of a shock in Hong Kong, lasts for about three days. Panel four shows Singapore's stock market response to its own domestic shocks. The fifth panel shows Singapore's response to shocks in the UK. Here we can see that Singapore's peak response occurs with a one day lag. From all five panels, we can see that the magnitude of Singapore's response to shock from Hong Kong is the highest (approx.0.65) followed by the US (0.5), Japan (0.3) and the UK (0.2). Hence we can say that Singapore is most sensitive to shocks from the Hong Kong and US market.

\subsection{Results for Multivariate GARCH Model and GJR Extensions}

Our main focus of this chapter is on the volatility spillover coefficients of the multivariate GARCH. The results will give us an insight into the degree of volatility spillover and the dynamics of volatility co-movement between the stock markets of North America, Europe and 
Asia. Tables 9, 10 and 11 present the results for three different systems of variance equations. We defined them to be Cases 1,2 and 3. The $\alpha_{A-B}$ coefficient measures the spillover effects of volatility from country B to country A. For example, $\alpha_{S G-H K}$ measures the volatility spillover from the Hong Kong market to the Singapore market. In the tables, (C) denotes contemporaneous spillovers while (L) denotes one-day lagged shocks. The spillover coefficients by no means imply causality. Rather, it reflects the degree of correlation and co-movement. It must be added that, the significance of the spillover coefficients does vary according to the lag structure stipulated. Hence, one should be discerning when interpreting the coefficients. Tables 12, 13 and 14 shows the parameter estimates for the variance equations with GJR specifications. Due to the large number of parameters being estimated simultaneously, the lag structure used and ordering of the markets do alter the significance of the coefficients.

\subsubsection{Singapore}

The opening hours of the Singapore market overlaps with that of Hong Kong and Japan while the US and UK markets opens and closes after the Asian markets and therefore affects Singapore, Hong Kong and Japan only on the following calendar day. Hence, when examining the spillover coefficients, we need to bear in mind if the markets are synchronous.

From Case 1; we can see that there is significant volatility spillover effects and volatility co-movement between the Singapore market and that of Hong Kong, US and UK. Volatility comovement between Singapore and the lagged innovations in the Hong Kong market is highly significant. This shows that the volatility spillover effects of Hong Kong on Singapore tend to be persistent. There is also significant volatility spillover from the UK market into the Singapore market.

In Case 2, we examine Hong Kong and Japanese shocks as being contemporaneous. When the innovations are contemporaneous, the spillover coefficients have a much higher value. This is because, the impact of the shocks are going to be higher than lagged shocks. In this lag structure, there is significant volatility co-movement between Singapore and Hong Kong.

In Case 3, volatility shocks in the Japanese market is introduced into the system as a contemporaneous innovation. Volatility co-movement is highly significant between Singapore and 
Japan. In all three cases, Singapore consistently exhibits significant volatility co-movement with the Hong Kong and US markets despite the lag structure stipulated.

In terms of influence and dominance, the Hong Kong and Japanese markets are much more influential than the Singapore market. Most of the studies done tend to conclude that spillover effects will be significant from the dominant market to the smaller market and that the effects are unidirectional i.e. volatility in the more influential market will affect volatility in the smaller market and not the other way round. However, it is interesting to note that over the last decade, there has been significant volatility spillover from the Singapore stock market to the Hong Kong and Japanese markets too. From case one, $\alpha_{H K-S G}$ is given as 0.05 and is highly significant. Similarly $\alpha_{J P-S G}$ coefficient is given as 0.02 , is highly significant implying that there is also significant volatility spillover from Singapore into the Japanese market.

Another interesting point to note is the significant lagged volatility spillover from Singapore to US (given by $\alpha_{U S-S G}(L)$ ) in case three. The implication of volatility spillover from Singapore to US is probably inconsequential for the US stock market considering the fact that the US stock market is a global leader both in terms of size and influence. However, the results obtained in this study show some volatility spillover from Singapore to US that is statistically significant. This may not be too surprising. There are over 1300 US corporations operating in Singapore and Singapore is America's tenth largest trading partner. With increased economic and financial integration and exportation of electronic goods to the US over the last decade (on $19^{\text {th }}$ Nov 2002, Singapore is the first ASEAN country to have a Free Trade Agreement with US), volatility spillover from Singapore to the US market is plausible, though the economic implication on US is negligible.

Upon including the GJR extensions, the following parameter estimates are obtained for the three lag structures. From Case 1, it can be seen that the lagged volatility spillover from Hong Kong, US, Japan and UK is significant. Though the magnitude of the coefficients is small, it is statistically significant. The $\gamma$ and $\lambda$ coefficients are significant. This implies that volatility shocks from Japan and UK are asymmetric. The $\gamma$ coefficient is greater than zero. This supports 
leverage effect. From Case 2 lag structure; there is a significant spillover effect from Hong Kong, US, Japan and the UK. In case two, $\phi, \eta, \lambda$ and $\gamma$ are not significant. In case two, the lag structure stipulation is such where all the volatility shocks are treated as contemporaneous. The spillover coefficients are all significant. However, volatility shocks are not seen to be asymmetric. In the Case 3 lag structure, volatility shocks from Japan are treated as contemporaneous. The $\gamma_{S G-J P}$ coefficient is significant. This means that volatility spillover from Japan into Singapore is asymmetric. Though the $\gamma_{S G-J P}$ coefficient is small in size, it is positive implying that leverage effect exists

\subsubsection{Hong Kong}

From all three cases, it can be inferred that contemporaneous volatility co-movement between Singapore and Hong Kong is highly significant. Both contemporaneous and lagged volatility spillovers from Hong Kong to Japan are also significant. Unlike Singapore, there is no significant volatility spillover from Hong Kong to US observed in all three cases. However, it must highlighted that other lag-structures might possibly yield results which show significant volatility spillover from Hong Kong to US. There is significant volatility co-movement between Hong Kong US, and UK. From case three, Hong Kong shows significant volatility co-movement with Japan. Upon, extending the model to include GJR extensions, it can be seen from Case 1 that there is significant volatility spillover from Singapore, US and UK. The $\phi_{H K-S G}$ is significant and greater than zero. This means that volatility spillover from Singapore into Hong Kong has an asymmetric impact and leverage effect exists. From Case 3, the contemporaneous volatility spillover from Japan and lagged spillover from the UK and US is significant. Only $\phi_{H K-S G}$ coefficient is positive and significant.

\subsubsection{Japan}

From Cases 2 and 3, we can see that there is significant volatility co-movement between Japan and stock markets of US and UK. Since the Japanese markets open and close before US and UK markets, the focus is on the lagged spillover coefficients. Examining the contemporaneous 
spillover coefficients of US and UK may not be relevant to Japan due to opening hours of the market. In both Cases 1 and 2, the $\alpha_{U S-J P}(L)$ and $\alpha_{U K-J P}(L)$ coefficients are significant.

From Case 3 with GJR extensions, $\gamma_{J P-U S}$ and $\lambda_{J P-U K}$ are both positive and significant. Volatility spillover from the US and UK markets into the Japanese markets is asymmetric. As for volatility spillover from Singapore to Japan, the $\phi_{J P-S G}$ coefficient though small in magnitude is highly significant.

\subsubsection{US}

It is evident from all of the three cases, that volatility spillover from US to all other markets is highly significant. The US market affects all four markets significantly, though the volatility spillovers are not just unidirectional from US to other markets. There are also significant volatility spillovers from UK into the US market. This can be explained by financial integration and increased interdependence between the economies. As the markets become more integrated, volatility co-movement becomes more pronounced. The results of this study show the possibility of volatility spillovers from smaller and less influential markets into global leaders markets such as the US stock market. Though the economic implications of such volatility spillover on US markets are left to be researched, such spillover from the smaller market is statistically significant.

From Case 1 lag structure with GJR extensions, we can note that even though the

spillover coefficients of $\alpha_{U S-S G}$ and $\alpha_{U S-H K}$ is small in magnitude, it is very significant. With increased economic and trade integration between the markets, it is highly plausible that there can be volatility spillovers from smaller markets into dominant markets. The economic ramifications on the dominant stock market may be negligible. However, the spillovers from the smaller to the dominant market have been found to be statistically significant. This is a very interesting result. Most studies only focus on spillovers from dominant markets to the smaller markets. However, this multivariate analysis shows that a volatility spillover from smaller markets such as Hong Kong and Singapore to a dominant and influential market such as the US is highly plausible. 


\subsubsection{UK}

From Case 1, we can see that there is significant spillover from UK into the Singapore markets. As evidenced by the results from the previous chapters, there is a very high degree of volatility co-movement between the US and UK markets. Our results are consistent with the results obtained by Engsted and Tanggard (2002) who confirm co-movement between the US and UK markets using a VAR model and bootstrap simulations.

From Cases 1, 2 and 3 with GJR specifications, it can be seen that there is a high degree of volatility spillover from the US to the UK and from UK to US. $\gamma_{U K-U S}$ in all three cases is positive and significant. This confirms that volatility spillover from US to the UK is asymmetric and leverage effects are present. Also from case two, we can see that there is significant volatility spillover from Japan to UK. This is given by $\alpha_{U K-J P}$. Asymmetric effects are also significant. This asymmetry is reflected by the coefficient $\lambda_{U K-J P}$.

\subsection{Implications for the Singapore market}

From analyzing the spillover coefficients, the multivariate analysis has confirmed that there is a very high degree of volatility co-movement between the Singapore stock market and those Hong Kong and US. If we were to order the markets according to the degree of volatility comovement with Singapore from the highest to the lowest, it will be: Hong Kong, US, Japan and UK. What is extremely interesting to note is that, when the markets are analyzed as one whole system, volatility shocks from Hong Kong and US does not have an asymmetric effect on volatility in the Singapore market as shown by all three cases. Volatility shocks from Japan exhibit asymmetry. This implies even though there is significant volatility spillover from Hong Kong and US, the $\phi$ and $\eta$ coefficients do not support asymmetry. Though there is significant volatility co-movement, negative shocks from Hong Kong and US does not increase volatility or leverage effects in the Singapore market. This is evidenced by all three lag structures. 


\section{CONCLUSIONS}

\subsection{Main Findings}

This paper examines the degree and nature of volatility co-movement between the Singapore stock market with that of US, UK, Hong Kong and Japan, the extent to which movements in the Singapore stock market can be explained by shocks in the four major markets and the nature of volatility spillovers between the Singapore stock market and that of US, UK, Hong Kong and Japan.

\subsubsection{Main Results of Univariate GARCH Analysis}

By building a GARCH $(1,1)$, EGARCH and GJR model for the full sample in order to capture the volatility dynamics of Singapore, Hong Kong, Japan, US and UK over a 10 year period, it was found that asymmetry is significant and supported in all five markets. The GJR model is more suited to capturing volatility dynamics in Singapore and Hong Kong while the EGARCH model performs better in capturing volatility dynamics of US, UK and Japan. Generally, shocks to the Singapore market tends to linger around for a longer period than it does in other stock markets. This may imply that the Singapore shows less market efficiency than the other markets as the effects of the shocks take a longer time to dissipate. The Singapore stock market shows much higher leverage effect than exhibited by Hong Kong, US, Japan and UK. The impact of bad news has a much greater effect on Singapore than it does on the other major markets.

\subsubsection{Main Results of Vector Autoregression and Impulse Response Analysis}

In order to study the co-movement of volatility of stock markets, we need to understand how shocks and volatility in one market is transmitted to other markets in a clearly recognizable fashion. Though VAR is not a volatility model, it allows us to look at the extent to which multilateral interaction exists between these markets and the structure of interdependence simultaneously. A VAR analysis is performed on the full sample 1992-2002. The variance decomposition results show that the Hong Kong stock market accounts for about $22 \%$ of the

forecast error variance of Singapore market while the US market accounts for about $12 \%$ of forecast error variance. Japan accounts for about $4 \%$ of the forecast error variances of Singapore while UK only $1 \%$. Geographically and economically close countries like Singapore and Hong 
Kong show strong linkages. Singapore is the most endogenous market in the system accounting for about only $60 \%$ of its own forecast error variances. Following the analysis on variance decomposition, impulse response technique was used to investigate the pattern of dynamic impulse response of Singapore to shocks in US, Japan, Hong Kong and UK. Singapore's response to shocks from US, Japan and UK lasts for about one day and becomes insignificant. However, Singapore's response to shocks from Hong Kong is persistent and the impact of shocks from the Hong Kong market lasts for about three days in the Singapore market.

The UK market was found to have very little influence over the Singapore market. Its influence over Singapore's forecast error variance has hovered around 1.5\% over the last decade. The Hong Kong and US stock markets are dominant in influencing the Singapore stock market. The US stock market has accounted for approximately $7 \%$ to $17 \%$ of Singapore's forecast error variance for the period 1992-2002.

\subsubsection{Main Results of Multivariate GARCH Analysis and Multivariate GARCH with GJR extensions}

To complete the analysis on volatility co-movement, a multivariate GARCH approach was used to analyze volatility in the five markets as a whole system. The multivariate approach allows for cross-market dynamics in the volatilities of the respective markets. The multivariate approach allows for modelling of volatility in the five markets simultaneously. The efficiency and power of the tests for cross-market co-movement and spillovers is greatly improved through a simultaneous analysis. I stipulate three different lag-structures to analyze volatility co-movement. I also extend the model by including GJR specifications to test for volatility.

The main results support a high degree of volatility co-movement between Hong Kong and US followed by Japan and UK. There is a very high degree of volatility co-movement between Singapore and Hong Kong and US. Volatility spillovers from Japan and UK into the Singapore market exhibit significant asymmetry.

An interesting find is that there is significant volatility spillover from Singapore to Hong Kong, Japan and the US. In terms of influence and dominance, the Hong Kong, Japanese and US markets are much more influential than the Singapore market. Most of the studies done previously tend to conclude that spillover effects will be significant from the dominant market to the smaller 
market and that the spillover effects are unidirectional. However, it is interesting to note that over the last decade, there has been small but significant volatility spillover from the Singapore stock market to the markets of Hong Kong, Japan and US.

\section{References}

Bekaert, G. and C.R. Harvey (1997), Emerging equity market volatility. Journal of Financial Economics 43, 29-77.

Bekaert, G. and G. Wu (2000), Asymmetric Volatility and Risk in Equity Markets. The Review of Financial Studies. Vol 13, No. 1, 1-42.

Bera, Anil K. and M.L. Higgins (1991), A Test for Conditional Heteroskedasticity in Time Series Models, Unpublished Manuscript (Department of Economics, University of Illinois, Champaign, IL)

Berndt, E.K., B.H. Hall, R.E. Hall and J.A. Hausman (1974), Estimation and Inference in Nonlinear Structural Models. Annals of Economic and Social Measurement.Vol 3, No. 4, 653-665

Bollerslev, T. (1986), Generalised Autoregressive Conditional Heteroskedasticity. Journal of Economterics, 31, 307-327.

Bollerslev, T., R.Y.Chou and K.F. Kroner (1992), ARCH Modeling in Finance: A Review of the Theory and Empirical Evidence. Journal of Econometrics, Vol 52, 5-59

Campbell , J.Y. and L. Hentschel (1992), No News is Good News : An Asymmetric Model of Changing Volatility in Stock Returns . Journal of Financial Economics. Vol 31 , $281-318$.

Daly, K.J. (1999), Financial Volatility and Real Economic Activity (Ashgate, England) , 1-32

De Santis, G. and S.Imrohoroglu, (1997), Stock Returns and Volatility in Emerging Financial Markets. Journal of International Money and Finance. Vol 16, No. 4 , 561-579.

Engle, R.F. (1982), Autoregressive Conditional Heteroscedasticity with Estimates of the Variance of UK Inflation. Econometrica. Vol 50. 987-1008

Engle, R.F. (1993), Statistical Models for Financial Volatility.Financial Analysts Journal, 49(1), 7278.

Engle, R.F. and Patton, A.J. , (2001), What is a Good Volatility Model ? Quantitative Finance, Vol 1, $237-245$.

Engle, R.F. and V.K. Ng (1993), Measuring and Testing the Impact of News on Volatility. The Journal of Finance. Vol 48, Issue 5, 1749 - 1778 .

Engsted, T. and C. Tanggard (2002), The Comovement of the US and UK stock markets. The Aarhus School of Business Working Paper, Denmark.

Eun, C.S. and S.Shim (1989), International Transmission of Stock Market Movements. The Journal of Financial and Quantitative Analysis, Vol 24, 241-256

Fratzscher, M. (2001) , Financial Market Integration in Europe: On the Effects of EMU on Stock Markets , ECB Working Paper 48.

Friedman, J. and Y. Shachmurove (1997), Co-movement of Major European Community Stock Markets : A Vector Autoregression Analysis. Global Finance Journal, Vol 8(2), 257-277

Glosten, L.R., R. Jaganathan, D.E. Runkle, (1993), On the Relation between the Expected Value and the Volatility of the Nominal Excess Return on Stocks. The Journal of Finance. Vol 48 , Issue 5 , 1779 $-1801$.

Guan Lim , K. and S. Wong, (1998). Financial Markets Trends and Studies of Singapore Futures Markets. Asia-Pacific Financial Markets. Vol 5, 45-63

Hamao, Y.R., R.W.Masulis and V.K.Ng (1990), Correlations in Price Changes and Volatility Across International Stock Markets. Review of Financial Studies, Vol 3, 281-307 
Janakiramanan, S. and A.S. Lamba (1998), An Empirical Examination of Linkages Between PacificBasin Stock Markets. Journal of International Financial Markets, Institutions and Money. Vol 8, 155 173

Johnson, R. and L. Soenen (2002), Asian Economic Integration and Stock Market Comovement. The Journal of Financial Research, Vol $25,141-157$

Karolyi, G.A. (1995), A Multivariate GARCH Model of International Transmissions of Stock Returns and Volatility: The Case of the United States and Canada. Journal of Business \& Economics Statistics. Vol 13, No. 1, 11-25

Karolyi, G.A. and R.M. Stultz (1996), Why Do Markets Move Together? An Investigation of U.S.Japan Stock Return Comovements. The Journal of Finance, Vol 51, 951-986

Kearney, C. (2000), The Determination and International Transmission of Stock Market Volatility. Global Finance Journal, Vol 11, 31-52

King, M.A. and S. Wadhwani , (1990), Transmission of Volatility between Stock Markets . The Review of Financial Studies. Vol 3, Issue 1, 5-33.

Koutmos , G. and G.G. Booth (1995), Asymmetric Volatility Transmission in International Stock Markets. Journal of International Money and Finance. Vol 14, No. 6 , 747-762.

Kroner, K.F. and V.K. Ng (1998), Modelling Asymmetric Comovements of Asset Returns. The Review of Financial Studies. Vol 11, No. 4, 817-844.

Lin, W., R.F. Engle and T .Ito (1994), Do Bulls and Bears Move Across Borders? International Transmission of Stock Returns and Volatility. The Review of Financial Studies, Vol 7, 507-538

Longin , F. and B. Solnik , (1995), Is the Correlation in International Equity Returns Constant : 1960 1990 ? Journal of International Money and Finance. Vol. 14, No. 1 , 3-26.

Nelson, D.B. (1991), Conditional Heteroskedasticity in Asset Returns: A New Approach. Econometrica, 59, 347-370.

Ng, A. (2000), Volatility Spillover Effects from Japan and the US to the Pacific-Basin, Journal of International Money and Finance, 19, 207-33

Park, J. and A.M. Fatemi (1993), The Linkages Between the Equity Markets of Pacific-Basin Countries and those of the U.S., U.K., and Japan: A Vector Autoregression Analysis. Global Finance Journal, Vol 4(1), 49-64

Poon, S-H and S.J. Taylor (1991), Stock Returns and Volatility : An Empirical Study of the UK Stock Market. Journal of Banking and Finance. Vol 16. 37-59.

Scheicher, M. (2001), The Comovements of Stock Markets in Hungary, Poland and The Czech Republic. International Journal of Finance and Economic. Vol 6. 27-39.

Schwert, G.W. (1989), Why does Stock Market Volatility Change Over Time ? The Journal of Finance, Vol 44 , Issue 5.

Schwert, G.W. (1998), Stock Market Volatility : Ten Years After the Crash . NBER Working Paper No.6381.

Sims, C.A. (1980), Macroeconomics and Reality. Econometrica, Vol 48, 1-48

Soydemir, G. (2000), International Transmission Mechanism of Stock Market Movements: Evidence from Emerging Equity Markets. Journal of Forecasting, Vol 19, 149-176

Wu , G. (2001), The Determinants of Asymmetric Volatility. The Review of Financial Studies. Vol 14, No.34, 837-859.

Zakoian, Jean-Michel (1990), Threshold Heteroskedastic Model, Unpublished Manuscript (INSEE, Paris) 


\section{Appendices}

Table 1: Market indices and market opening and closing times

\begin{tabular}{|c|c|c|c|c|}
\hline Country & Index & Abbreviation & Local Time & GMT \\
\hline Hong Kong & Hang Seng & Hang Seng & $\begin{array}{l}10: 00-12: 30 \\
2.30-3.30\end{array}$ & $\begin{array}{l}02: 00-04: 30 \\
06: 30-07: 30\end{array}$ \\
\hline Japan & Nikkei 225 & Nikkei 225 & $\begin{array}{l}09: 00-11: 00 \\
12: 30-03: 00\end{array}$ & $\begin{array}{l}00: 00-02: 00 \\
03: 30-06: 00\end{array}$ \\
\hline Singapore & $\begin{array}{l}\text { Straits Times } \\
\text { Industrial }\end{array}$ & STI & $\begin{array}{l}09: 00-12: 30 \\
2: 00-4: 00\end{array}$ & $\begin{array}{l}01: 00-05: 30 \\
06: 00-08: 00\end{array}$ \\
\hline UK & FTSE 100 & FTSE 100 & $8: 30-4: 30$ & $08: 30-16: 30$ \\
\hline US & $\begin{array}{l}\text { Dow Jones } \\
\text { Industrial Average }\end{array}$ & DJIA & $9: 30-4: 00$ & $14: 30-21: 00$ \\
\hline
\end{tabular}

Table 2: Unconditional correlation coefficients between daily market returns in local currency terms '92-'02

\begin{tabular}{llllll}
\hline & Singapore & US (-1)** & Hong Kong & Japan & UK \\
\hline Singapore & - & & & \\
US (-1) ** & 0.34 & - & & \\
& $(0.0)^{*}$ & & & \\
Hong Kong & 0.60 & 0.35 & - & \\
& $(0.0)^{*}$ & $(0.0)^{*}$ & & \\
Japan & 0.30 & 0.24 & 0.33 & - \\
& $(0.0)^{*}$ & $(0.0)^{*}$ & $(0.0)^{*}$ & & \\
UK(-1) & 0.27 & 0.28 & 0.30 & 0.23 & - \\
& $(0.0)^{*}$ & $(0.0)^{*}$ & $(0.0)^{*}$ & $(0.0)^{*}$ & \\
\hline
\end{tabular}

* Correlation at $10 \%$ level of significance

** Corresponds to the one-day lagged return in the US and UK markets.

Table 3: Descriptive statistics for daily market returns in local currency terms: '92-'02

\begin{tabular}{llllll}
\hline & Singapore & USA & Japan & Hong Kong & UK \\
\hline Mean & 0.01 & 0.04 & -0.03 & 0.03 & 0.02 \\
Maximum & 14.87 & 6.15 & 7.66 & 17.25 & 5.44 \\
Minimum & -9.67 & -7.45 & -7.23 & -14.73 & -5.89 \\
Std. Dev. & 1.37 & 1.00 & 1.47 & 1.77 & 1.04 \\
Skewness & 0.35 & -0.37 & 0.17 & 0.03 & -0.17 \\
Kurtosis & 14.13 & 8.64 & 5.47 & 11.79 & 5.96 \\
Jarque-Bera & 14407.65 & 3753.11 & 724.03 & 8948.88 & 1027.16 \\
\hline
\end{tabular}


Figure 1: Plot of STI Index from '92-'02

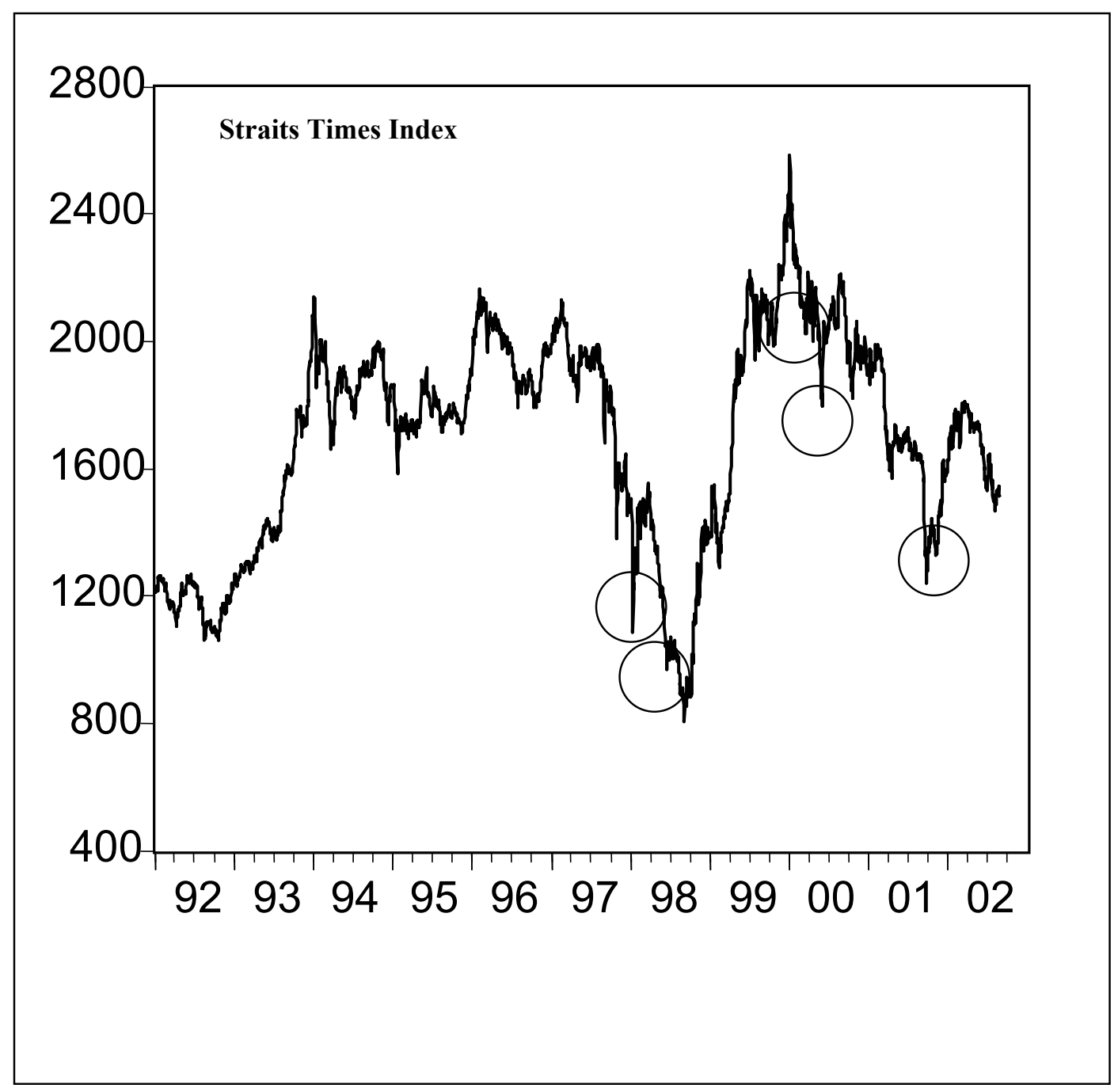


Figure 2: Plot of stock price indices for Singapore, Hong Kong, Japan, US \& UK
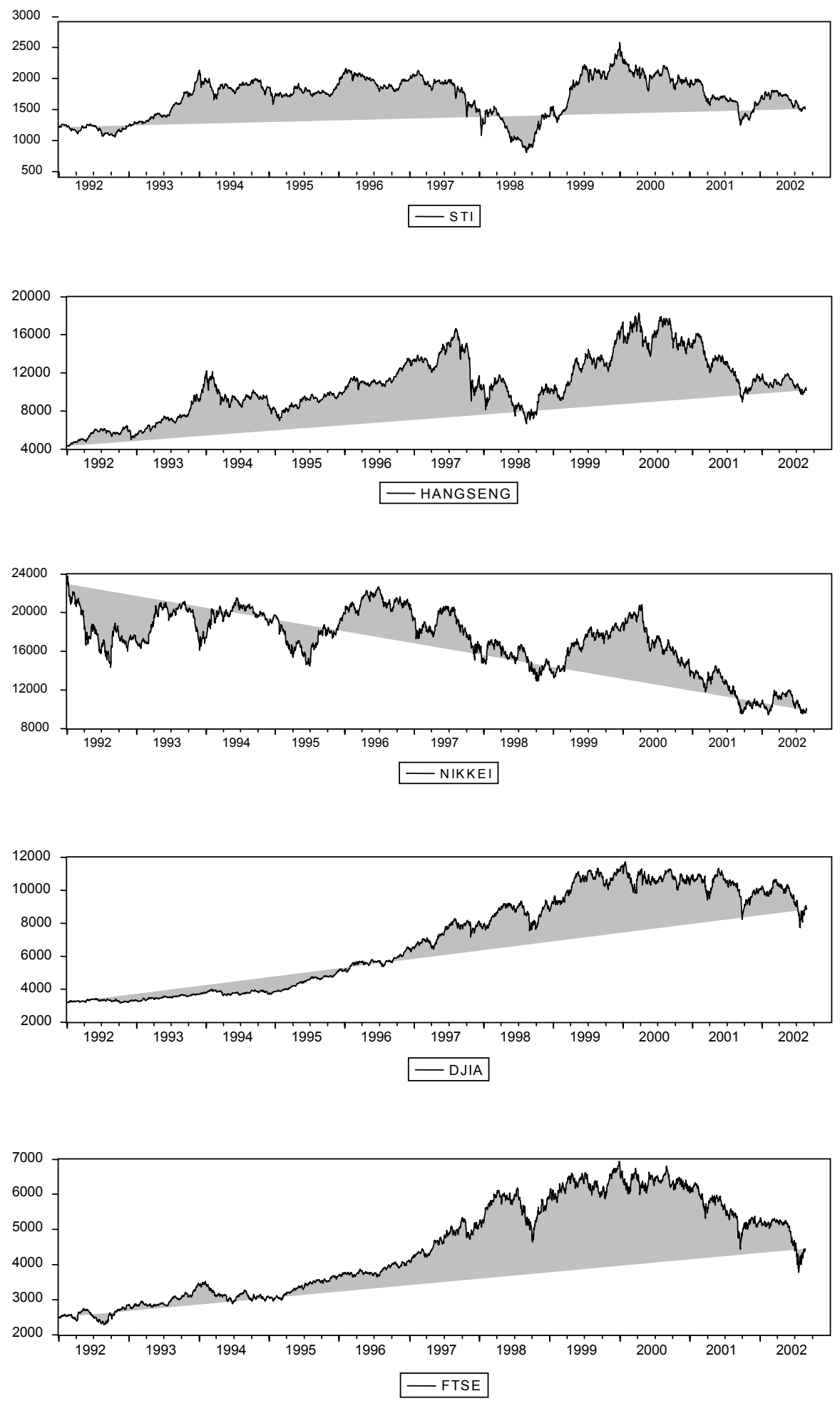
Figure 2: Plot of returns for Singapore, Hong Kong, Japan, US \& UK
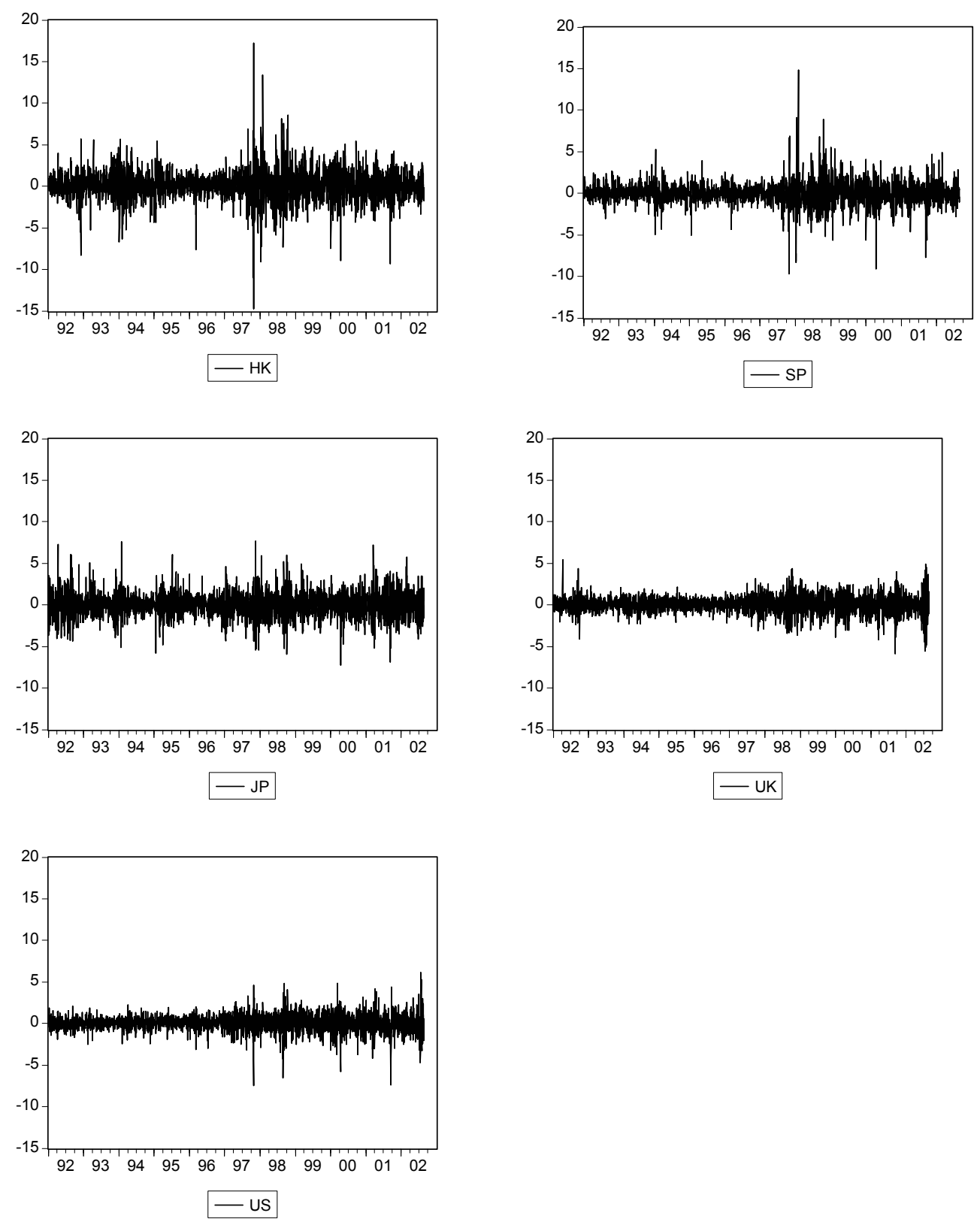
Table 4: Parameter estimates from fitting AR (p) for Singapore, Hong Kong, Japan, US \& UK from 1992-2002

\begin{tabular}{|c|c|c|c|c|c|}
\hline Country & Singapore & Hong Kong & Japan & US & UK \\
\hline \multicolumn{6}{|l|}{ Parameter estimates } \\
\hline $\mathrm{AR}(1)$ & $0.14(0.0)^{*}$ & $0.03(0.13)$ & $-0.05(0.01)^{*}$ & $0.02(0.21)$ & $0.05(0.01)^{*}$ \\
\hline $\operatorname{AR}(2)$ & - & $-0.03(0.09)^{*}$ & - & $-0.04(0.02)^{*}$ & $-0.06(0.0)^{*}$ \\
\hline $\operatorname{AR}(3)$ & - & $0.09(0.0)^{*}$ & - & - & $-0.07(0.0)^{*}$ \\
\hline AIC & 3.45 & 3.97 & 3.61 & 2.84 & 2.9 \\
\hline SIC & 3.45 & 3.99 & 3.61 & 2.85 & 2.9 \\
\hline Log Likelihood & -4786.54 & -5516.23 & -5010.92 & -3941.98 & -4021.16 \\
\hline $\mathrm{Q}(10)$ & $0.01(0.35)$ & $0.02(0.19)$ & $-0.01(0.32)$ & $0.05(0.30)$ & $-0.018(0.1)$ \\
\hline $\mathrm{Q}^{2}(10)$ & $0.15(0.0)^{*}$ & $0.07(0.0)^{*}$ & $0.07(0.0)^{*}$ & $0.09(0.0)^{*}$ & $0.23(0.0)^{*}$ \\
\hline
\end{tabular}


Table 5: Parameter estimates of fitting GARCH $(1,1)$, EGARCH and GJR for Singapore, Hong Kong, Japan, US and UK for 1992 - 2002

\begin{tabular}{|c|c|c|c|}
\hline Model & GARCH $(1,1)$ & EGARCH & GJR/TARCH \\
\hline \multicolumn{4}{|l|}{ Parameter estimates } \\
\hline \multicolumn{4}{|l|}{ SINGAPORE } \\
\hline $\operatorname{AR}(1)$ & $0.15(0.0)^{*}$ & $0.15(0.0)^{*}$ & $0.15(0.0)^{*}$ \\
\hline$\omega$ & $0.04(0.0)^{*}$ & $0.15(0.0)^{*}$ & $0.03(0.0)^{*}$ \\
\hline$\alpha_{1}$ & $0.13(0.0)^{*}$ & $0.20(0.0)^{*}$ & $0.07(0.0)^{*}$ \\
\hline$\beta_{1}$ & $0.86(0.0)^{*}$ & $0.98(0.0)^{*}$ & $0.87(0.0)^{*}$ \\
\hline$\gamma_{1}$ & - & $-0.06(0.01)^{*}$ & $0.17(0.0)^{*}$ \\
\hline AIC/SIC & $3.11 / 3.12$ & $3.10 / 3.11$ & $3.09 / 3.11$ \\
\hline Log Likelihood & -4312.54 & -4299.75 & -4290.90 \\
\hline \multicolumn{4}{|l|}{ HONG KONG } \\
\hline $\mathrm{AR}(1)$ & $0.08(0.0)^{*}$ & $0.10(0.0)^{*}$ & $0.09(0.0)^{*}$ \\
\hline $\operatorname{AR}(2)$ & $0.01(0.74)$ & $0.02(0.4)$ & $0.01(0.53)$ \\
\hline $\operatorname{AR}(3)$ & $0.05(0.02)^{*}$ & $0.06(0.0)^{*}$ & $0.07(0.0)^{*}$ \\
\hline$\omega$ & $0.04(0.0)^{*}$ & $0.10(0.0)^{*}$ & $0.05(0.0)^{*}$ \\
\hline$\alpha_{1}$ & $0.09(0.0)^{*}$ & $0.16(0.0)^{*}$ & $0.02(0.0)^{*}$ \\
\hline$\beta_{1}$ & $0.9(0.0)^{*}$ & $0.98(0.0)^{*}$ & $0.90(0.0)^{*}$ \\
\hline$\gamma_{1}$ & - & $-0.08(0.0)^{*}$ & $0.11(0.0)^{*}$ \\
\hline $\mathrm{AIC} / \mathrm{SIC}$ & $3.70 / 3.72$ & $3.68 / 3.70$ & $3.6 / 3.70$ \\
\hline Log Likelihood & -5135.12 & -5100.43 & -5100.17 \\
\hline \multicolumn{4}{|l|}{ JAPAN } \\
\hline $\mathrm{AR}(1)$ & $-0.04(0.03)^{*}$ & $-0.04(0.03)^{*}$ & $-0.04(0.04)^{*}$ \\
\hline$\omega$ & $0.06(0.0)^{*}$ & $0.08(0.0)^{*}$ & $0.05(0.01)^{*}$ \\
\hline$\alpha_{1}$ & $0.08(0.0)^{*}$ & $0.17(0.0)^{*}$ & $0.02(0.06)^{*}$ \\
\hline$\beta_{1}$ & $0.9(0.0)^{*}$ & $0.97(0.0)^{*}$ & $0.91(0.0)^{*}$ \\
\hline$\gamma_{1}$ & - & $-0.08(0.0)^{*}$ & $0.10(0.0)^{*}$ \\
\hline $\mathrm{AIC} / \mathrm{SIC}$ & $3.49 / 3.50$ & $3.47 / 3.48$ & $3.47 / 3.48$ \\
\hline Log Likelihood & -4840.14 & -4809.67 & -4811.01 \\
\hline \multicolumn{4}{|l|}{ US } \\
\hline $\mathrm{AR}(1)$ & $0.04(0.08)^{*}$ & $0.04(0.04)^{*}$ & $0.05(0.02)^{*}$ \\
\hline$\omega$ & $0.01(0.01)^{*}$ & $0.09(0.0)^{*}$ & $0.01(0.0)^{*}$ \\
\hline$\alpha_{1}$ & $0.07(0.0)^{*}$ & $0.11(0.0)^{*}$ & $0.01(0.31)$ \\
\hline$\beta_{1}$ & $0.92(0.0)^{*}$ & $0.98(0.0)^{*}$ & $0.92(0.0)^{*}$ \\
\hline$\gamma_{1}$ & - & $-0.09(0.0)^{*}$ & $0.11(0.0)^{*}$ \\
\hline $\mathrm{AIC} / \mathrm{SIC}$ & $2.60 / 2.61$ & $2.57 / 2.58$ & $2.58 / 2.59$ \\
\hline Log Likelihood & -3602.51 & -3565.98 & -3574.46 \\
\hline \multicolumn{4}{|l|}{ UK } \\
\hline $\operatorname{AR}(1)$ & $0.06(0.0)^{*}$ & $0.06(0.0)^{*}$ & $0.06(0.0)^{*}$ \\
\hline$\omega$ & $0.01(0.01)^{*}$ & $0.08(0.0)^{*}$ & $0.01(0.0)^{*}$ \\
\hline$\alpha_{1}$ & $0.08(0.0)^{*}$ & $0.11(0.0)^{*}$ & $0.01(0.29)$ \\
\hline$\beta_{1}$ & $0.91(0.0)^{*}$ & $0.98(0.0)^{*}$ & $0.92(0.0)^{*}$ \\
\hline$\gamma_{1}$ & - & $-0.07(0.0)^{*}$ & $0.13(0.0)^{*}$ \\
\hline AIC/SIC & $2.66 / 2.67$ & $2.64 / 2.65$ & $2.64 / 2.66$ \\
\hline Log Likelihood & -3686.96 & -3661.41 & -3664.66 \\
\hline
\end{tabular}

The p-values are indicated in the parentheses. I check for $10 \%$ level of significance. P-values greater than 0.1 indicate insignificance while $\mathrm{p}$-values less than 0.1 indicates significance. ${ }^{*}$ denotes statistical significance at the $10 \%$ level 
Table 6: Results of the unit root test

\begin{tabular}{lllc}
\hline & ADF & PP & Optimal Lag Length \\
\hline U.S.A & $-32.67^{*}$ & $-162.9^{*}$ & 8 \\
Japan & $-24.23^{*}$ & $-224.77^{*}$ & 14 \\
Hong Kong & $-25.07^{*}$ & $-204.32^{*}$ & 13 \\
Singapore & $-27.61^{*}$ & $-172.01^{*}$ & 12 \\
U.K. & $-25^{*}$ & $-197.08^{*}$ & 14 \\
\hline *Statistically significant at specified optimal lag length at the 1\% level \\
\hline
\end{tabular}

Table 7: Vector Autoregression Estimates 1992-2002

\begin{tabular}{|c|c|c|c|c|c|}
\hline & USA & Japan & Hong Kong & Singapore & UK \\
\hline US(-1) & $-0.00[-0.02]$ & $0.28[9.80]^{*}$ & $0.52[15.34]^{*}$ & $0.39[14.86]^{*}$ & $0.32[15.72]^{*}$ \\
\hline US(-2) & $-0.05[-2.13]^{*}$ & $-0.00[-0.01]$ & $-0.10[-2.77]^{*}$ & $-0.10[-3.44]^{*}$ & $0.05[2.23]^{*}$ \\
\hline Japan(-1) & $-0.02[-1.61]$ & $-0.10[-4.78]^{*}$ & $-0.09[-4.10]^{*}$ & $-0.05[-2.62]^{*}$ & $-0.06[-4.05]^{*}$ \\
\hline Japan(-2) & $-0.01[-0.65]$ & $-0.03[-1.61]$ & $-0.01[-0.27]$ & $0.01[0.75]$ & $-0.03[-2.33]^{*}$ \\
\hline Hong Kong(-1) & $-0.01[-0.76]$ & $-0.03[-1.51]$ & $-0.04[-2.06]^{*}$ & $0.02[1.03]$ & $0.00[0.16]$ \\
\hline Hong Kong(-2) & $0.02[1.57]$ & $0.01[0.49]$ & $-0.01[-0.54]$ & $0.03[1.72]^{*}$ & $0.03[1.98]^{*}$ \\
\hline Singapore(-1) & $0.01[0.64]$ & $0.01[0.36]$ & $0.05[1.79]^{*}$ & $0.10[4.29]^{*}$ & $-0.03[-1.90]^{*}$ \\
\hline Singapore(-2) & $-0.01[-0.47]$ & $0.02[0.63]$ & $-0.03[-0.90]$ & $-0.01[-0.57]$ & $0.00[0.04]$ \\
\hline UK(-1) & $0.07[3.65]^{*}$ & $0.22[7.37]^{*}$ & $0.30[8.46]^{*}$ & $0.15[5.60]^{*}$ & $-0.05[-2.34]^{*}$ \\
\hline UK(-2) & $-0.03[-1.26]^{*}$ & $-0.03[-0.85]$ & $0.07[1.91]^{*}$ & $-0.00[-0.18]$ & $-0.07[-3.32]^{*}$ \\
\hline Constant & $0.03[1.89]^{*}$ & $-0.04[-1.79]^{*}$ & $0.01[2.22]^{*}$ & $-0.01[-0.36]$ & $0.01[0.32]$ \\
\hline Log Likelihood & -21735.40 & & & & \\
\hline AIC & 15.69 & & & & \\
\hline SIC & 15.81 & & & & \\
\hline $\begin{array}{l}\text { t-statistics are ind } \\
\text { 1.645. Statistical }\end{array}$ & $\begin{array}{l}\text { ted in the bracl } \\
\text { nificance is der }\end{array}$ & $\begin{array}{l}\text { ts. The } 10 \% \text { cri } \\
\text { ted by } *\end{array}$ & al for a two-ta & test with larg & $(>120)$ is \\
\hline
\end{tabular}


Table 8: Variance Decompositions

Market ordering : US, Japan, Hong Kong, Singapore, UK

\begin{tabular}{|c|c|c|c|c|c|c|}
\hline & & Innova & market & & & \\
\hline $\begin{array}{l}\text { Variance } \\
\text { Decomposition in } \\
\text { markets of: }\end{array}$ & Horizon(days) & US & Japan & $\begin{array}{l}\text { Hong } \\
\text { Kong }\end{array}$ & Singapore & U.K. \\
\hline \multirow[t]{3}{*}{ US } & 5 & 99.24 & 0.07 & 0.06 & 0.04 & 0.58 \\
\hline & 10 & 99.24 & 0.07 & 0.06 & 0.04 & 0.58 \\
\hline & 15 & 99.24 & 0.07 & 0.06 & 0.04 & 0.58 \\
\hline \multirow[t]{3}{*}{ Japan } & 5 & 6.54 & 91.54 & 0.02 & 0.02 & 1.87 \\
\hline & 10 & 6.54 & 91.54 & 0.02 & 0.02 & 1.87 \\
\hline & 15 & 6.54 & 91.54 & 0.02 & 0.02 & 1.87 \\
\hline \multirow[t]{3}{*}{ Hong Kong } & 5 & 12.99 & 5.26 & 79.18 & 0.19 & 2.36 \\
\hline & 10 & 12.99 & 5.26 & 79.18 & 0.19 & 2.36 \\
\hline & 15 & 12.99 & 5.26 & 79.18 & 0.19 & 2.36 \\
\hline \multirow[t]{3}{*}{ Singapore } & 5 & 12.41 & 4.22 & 21.90 & 60.45 & 1.01 \\
\hline & 10 & 12.41 & 4.22 & 21.90 & 60.45 & 1.01 \\
\hline & 15 & 12.41 & 4.22 & 21.90 & 60.45 & 1.01 \\
\hline \multirow[t]{3}{*}{ UK } & 5 & 21.13 & 2.64 & 2.82 & 0.39 & 73.01 \\
\hline & 10 & 21.13 & 2.64 & 2.82 & 0.39 & 73.01 \\
\hline & 15 & 21.13 & 2.64 & 2.82 & 0.39 & 73.01 \\
\hline
\end{tabular}


Figure 3 :Response of Singapore to shocks in US, Japan, Hong Kong, Singapore \& UK

Response to Cholesky One S.D. Innovations \pm 2 S.E.
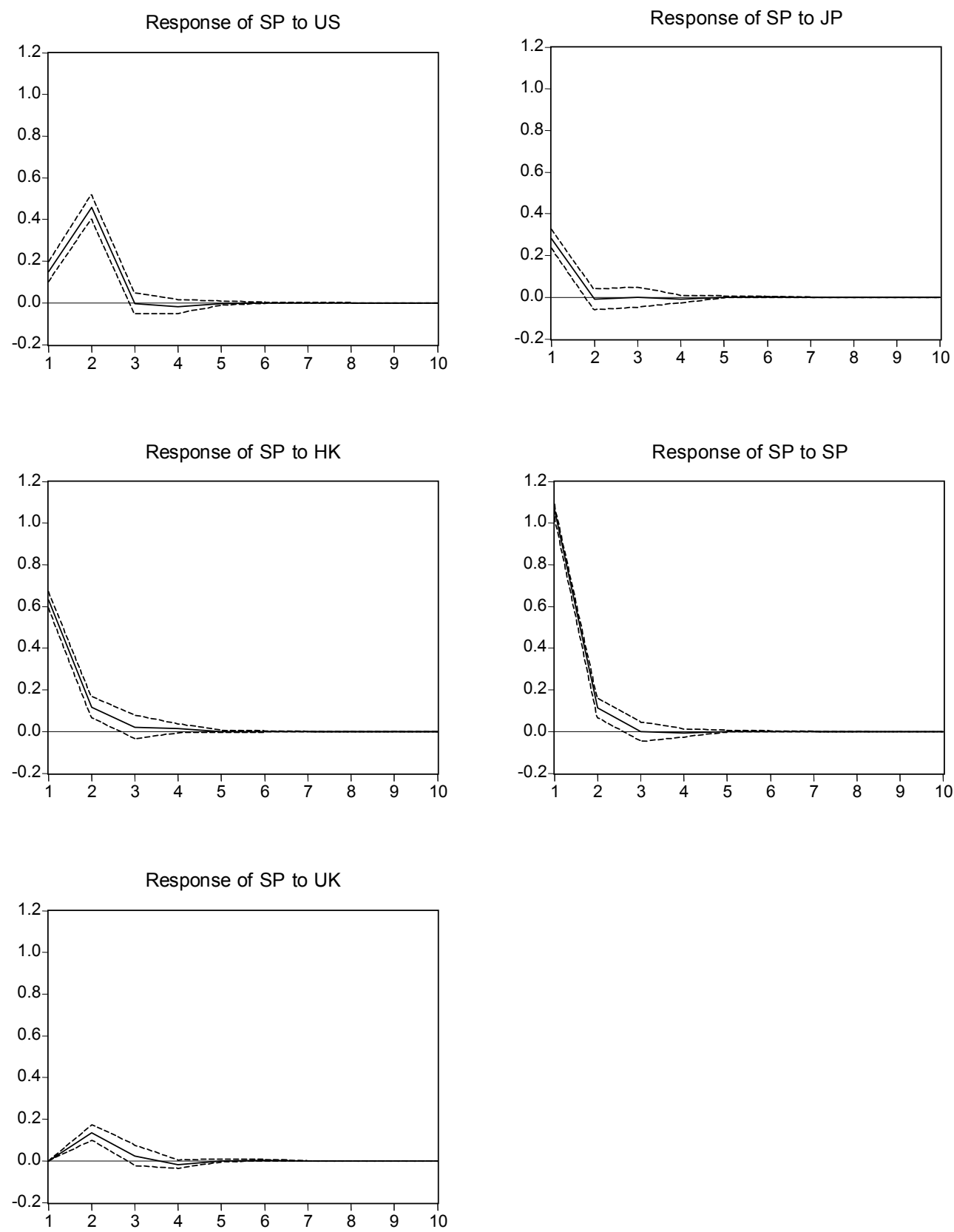


\begin{tabular}{|c|c|c|c|c|c|c|c|c|}
\hline \multirow[b]{2}{*}{ Country } & \multirow[b]{2}{*}{$\omega$} & \multirow[b]{2}{*}{$\beta$} & \multirow[b]{2}{*}{$\alpha$} & \multicolumn{5}{|c|}{ Spillover effects from SG, HK, US,JP \& UK into country } \\
\hline & & & & Singapore & Hong Kong & US & Japan & UK \\
\hline Singapore & $0.03(0.00)^{*}$ & $0.84(0.00)^{*}$ & $0.07(0.00)^{*}$ & -- & $0.02(0.00) *(\mathrm{~L})$ & $0.03(0.00)^{*}(\mathrm{~L})$ & $-0.004(0.10)(\mathrm{L})$ & $0.02(0.00)^{*}(\mathrm{~L})$ \\
\hline Hong Kong & $0.09(0.00)^{*}$ & $0.85(0.00)^{*}$ & $0.07(0.00)^{*}$ & $0.05(0.00)^{*}(\mathrm{C})$ & -- & $0.01(0.47)(\mathrm{L})$ & $0.004(0.27)(\mathrm{C})$ & $0.01(0.52)(\mathrm{L})$ \\
\hline US & $0.02(0.00)^{*}$ & $0.87(0.00)^{*}$ & $0.06(0.00)^{*}$ & $0.00(0.56)(\mathrm{C})$ & $-0.00(0.22)(\mathrm{C})$ & -- & $-0.003(0.00)^{*}(\mathrm{~L})$ & $0.05(0.00)^{*}(\mathrm{C})$ \\
\hline Japan & $0.07(0.00)^{*}$ & $0.87(0.00)^{*}$ & $0.08(0.00)^{*}$ & $0.02(0.00)^{*}(\mathrm{C})$ & $-0.01(0.00)^{*}(\mathrm{~L})$ & $-0.00(0.85)(\mathrm{C})$ & -- & $0.01(0.21)(\mathrm{L})$ \\
\hline UK & $0.07(0.00)^{*}$ & $0.72(0.00)^{*}$ & $0.15(0.00)^{*}$ & $0.01(0.00) *(\mathrm{C})$ & $0.00(0.90)(\mathrm{C})$ & $0.02(0.03) *(\mathrm{~L})$ & $0.01(0.00) *(\mathrm{C})$ & -- \\
\hline Log-Likelih & $7 \quad$ *Indicate & icance at $10 \%$ & & & & & & \\
\hline
\end{tabular}

\begin{tabular}{|c|c|c|c|c|c|c|c|c|}
\hline \multirow[b]{2}{*}{ Country } & \multirow[b]{2}{*}{$\omega$} & \multirow[b]{2}{*}{$\beta$} & \multirow[b]{2}{*}{$\alpha$} & \multicolumn{5}{|c|}{ Spillover effects from SG, HK, US,JP \& UK into country } \\
\hline & & & & Singapore & Hong Kong & US & Japan & UK \\
\hline Singapore & $0.05(0.00)^{*}$ & $0.74(0.00)^{*}$ & $0.08(0.00)^{*}$ & -- & $0.05(0.00)^{*}(\mathrm{C})$ & $0.05(0.00)^{*}(\mathrm{C})$ & $0.003(0.4)(\mathrm{C})$ & $0.01(0.2)(\mathrm{C})$ \\
\hline Hong Kong & $0.07(0.00)^{*}$ & $0.86(0.00)^{*}$ & $0.07(0.00)^{*}$ & $0.01(0.52)(\mathrm{L})$ & -- & $0.03(0.00) *(\mathrm{C})$ & $0.00(0.98)(\mathrm{L})$ & $0.03(0.00)^{*}(\mathrm{C})$ \\
\hline US & $0.01(0.00)^{*}$ & $0.88(0.00)^{*}$ & $0.07(0.00)^{*}$ & $0.00(0.96)(\mathrm{L})$ & $-0.00(0.22)(\mathrm{L})$ & -- & $-0.001(0.19)(\mathrm{C})$ & $0.04(0.00)^{*}(\mathrm{~L})$ \\
\hline Japan & $0.10(0.00)^{*}$ & $0.84(0.00)^{*}$ & $0.08(0.00)^{*}$ & $-0.01(0.00)^{*}(\mathrm{~L})$ & $0.02(0.00) *(C)$ & $-0.02(0.01)^{*}(\mathrm{~L})$ & -- & $0.06(0.00)^{*}(\mathrm{C})$ \\
\hline UK & $0.05(0.00)^{*}$ & $0.79(0.00)^{*}$ & $0.11(0.00)^{*}$ & $-0.002(0.32)(\mathrm{L})$ & $0.001(0.51)(\mathrm{L})$ & $0.04(0.00) *(\mathrm{C})$ & $0.01(0.00) *(\mathrm{~L})$ & -- \\
\hline
\end{tabular}

\begin{tabular}{|c|c|c|c|c|c|c|c|c|}
\hline \multirow[b]{2}{*}{ Country } & \multirow[b]{2}{*}{$\omega$} & \multirow[b]{2}{*}{$\beta$} & \multirow[b]{2}{*}{$\alpha$} & \multicolumn{5}{|c|}{ Spillover effects from SG, HK, US,JP \& UK into country } \\
\hline & & & & Singapore & Hong Kong & US & Japan & UK \\
\hline Singapore & $0.27(0.00)^{*}$ & $0.49(0.00)^{*}$ & $0.11(0.00)^{*}$ & -- & $0.03(0.00) *(\mathrm{~L})$ & $0.09(0.00)^{*}(\mathrm{~L})$ & $0.02(0.00)^{*}(\mathrm{C})$ & $0.10(0.00)^{*}(\mathrm{~L})$ \\
\hline Hong Kong & $0.29(0.00)^{*}$ & $0.67(0.00)^{*}$ & $0.11(0.00)^{*}$ & $0.05(0.01)^{*}(\mathrm{~L})$ & -- & $0.11(0.00)^{*}(\mathrm{~L})$ & $0.02(0.02)^{*}(\mathrm{C})$ & $0.07(0.00)^{*}(\mathrm{~L})$ \\
\hline US & $0.14(0.00)^{*}$ & $0.54(0.00)^{*}$ & $0.09(0.00)^{*}$ & $0.02(0.00)^{*}(\mathrm{~L})$ & $-0.003(0.10)(\mathrm{L})$ & -- & $0.00(0.74)(\mathrm{C})$ & $0.16(0.00)^{*}(\mathrm{C})$ \\
\hline Japan & $0.15(0.00)^{*}$ & $0.82(0.00)^{*}$ & $0.06(0.00)^{*}$ & $-0.00(0.69)(\mathrm{L})$ & $0.01(0.11)(\mathrm{L})$ & $0.01(0.23)(\mathrm{L})$ & -- & $0.06(0.00)^{*}(\mathrm{~L})$ \\
\hline UK & $0.11(0.00)^{*}$ & $0.66(0.00)^{*}$ & $0.13(0.00)^{*}$ & $0.02(0.00) *(\mathrm{~L})$ & $-0.01(0.00)^{*}(\mathrm{~L})$ & $0.05(0.00) *(\mathrm{~L})$ & $0.02(0.00)^{*}(\mathrm{C})$ & -- \\
\hline
\end{tabular}




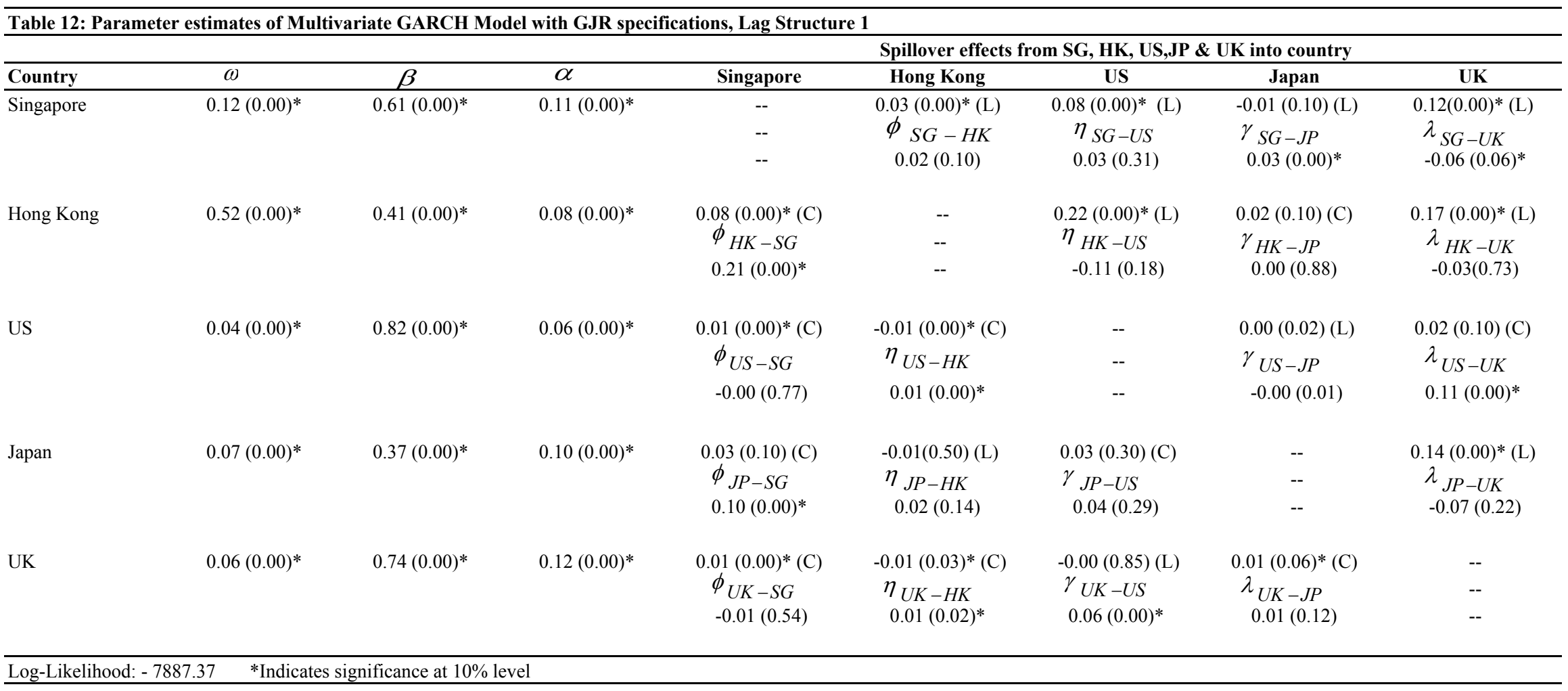




\begin{tabular}{|c|c|c|c|c|c|c|c|c|}
\hline \multirow[b]{2}{*}{ Country } & \multirow[b]{2}{*}{$\omega$} & \multirow[b]{2}{*}{$\beta$} & \multirow[b]{2}{*}{$\alpha$} & \multicolumn{5}{|c|}{ Spillover effects from SG, HK, US,JP \& UK into country } \\
\hline & & & & Singapore & Hong Kong & US & Japan & UK \\
\hline \multirow[t]{3}{*}{ Singapore } & $0.42(0.00)^{*}$ & $0.20(0.00)^{*}$ & $0.12(0.00)^{*}$ & -- & $0.07(0.00)^{*}(\mathrm{C})$ & $0.06(0.01)^{*}(\mathrm{C})$ & $0.02(0.00)^{*}(\mathrm{C})$ & $0.05(0.02) *(\mathrm{C})$ \\
\hline & & & & -- & $\phi_{S G-H K}$ & $\eta_{S G-U S}$ & $\gamma_{S G-J P}$ & $\lambda_{S G-U K}$ \\
\hline & & & & -- & $0.02(0.15)$ & $0.04(0.34)$ & $-0.01(0.42)$ & $-0.02(0.50)$ \\
\hline \multirow[t]{3}{*}{ Hong Kong } & $1.35(0.00)^{*}$ & $0.13(0.00)^{*}$ & $0.11(0.00)^{*}$ & $0.07(0.00)^{*}(\mathrm{~L})$ & -- & $0.07(0.00)^{*}(\mathrm{C})$ & $0.07(0.00)^{*}(\mathrm{~L})$ & $0.08(0.00)^{*}(\mathrm{C})$ \\
\hline & & & & $\phi_{H K}-S G$ & -- & $\eta_{H K-U S}$ & $\gamma_{H K-J P}$ & $\lambda_{H K-U K}$ \\
\hline & & & & $0.11(0.00)^{*}$ & -- & $0.06(0.26)$ & $-0.06(0.01)^{*}$ & $-0.01(0.89)$ \\
\hline \multirow[t]{3}{*}{ US } & $0.35(0.00)^{*}$ & $0.13(0.00)^{*}$ & $0.16(0.00)^{*}$ & $0.05(0.00)^{*}(\mathrm{~L})$ & $0.01(0.05) *(\mathrm{~L})$ & -- & $0.02(0.01)^{*}(\mathrm{C})$ & $0.05(0.00)^{*}(\mathrm{~L})$ \\
\hline & & & & $\phi_{U S-S G}$ & $\eta_{U S}-H K$ & -- & $\gamma_{U S-J P}$ & $\lambda_{U S-U K}$ \\
\hline & & & & $0.05(0.01)^{*}$ & $-0.00(0.46)$ & -- & $-0.01(0.49)$ & $0.16(0.00)^{*}$ \\
\hline \multirow[t]{3}{*}{ Japan } & $1.04(0.00)^{*}$ & $0.20(0.00)^{*}$ & $0.08(0.00)^{*}$ & $0.03(0.21)(\mathrm{L})$ & $0.03(0.02)^{*}(\mathrm{C})$ & $0.04(0.20)(\mathrm{L})$ & -- & $0.11(0.00) *(\mathrm{C})$ \\
\hline & & & & $\phi_{J P-S G}$ & $\eta_{J P-H K}$ & $\gamma_{J P-U S}$ & -- & $\lambda_{J P-U K}$ \\
\hline & & & & $-0.04(0.29)$ & $0.04(0.07)^{*}$ & $0.08(0.10)$ & -- & $-0.02(0.74)$ \\
\hline \multirow[t]{3}{*}{ UK } & $0.15(0.00)^{*}$ & $0.40(0.00)^{*}$ & $0.13(0.00)^{*}$ & $0.02(0.00)^{*}(\mathrm{~L})$ & $0.01(0.19)(\mathrm{L})$ & $0.09(0.00)^{*}(\mathrm{C})$ & $0.02(0.01)^{*}(\mathrm{~L})$ & -- \\
\hline & & & & $\phi_{U K-S G}$ & $\eta_{U K}-H K$ & $\gamma_{U K-U S}$ & $\lambda_{U K-J P}$ & -- \\
\hline & & & & $0.05(0.00)^{*}$ & $-0.01(0.01)^{*}$ & $0.08(0.01)^{*}$ & $0.06(0.00)^{*}$ & -- \\
\hline Log-Likeli & *Indic & cance at 10 & & & & & & \\
\hline
\end{tabular}




\begin{tabular}{|c|c|c|c|c|c|c|c|c|}
\hline \multirow[b]{2}{*}{ Country } & \multirow[b]{2}{*}{$\omega$} & \multirow[b]{2}{*}{$\beta$} & \multirow[b]{2}{*}{$\alpha$} & \multicolumn{5}{|c|}{ Spillover effects from SG, HK, US,JP \& UK into country } \\
\hline & & & & Singapore & Hong Kong & US & Japan & UK \\
\hline \multirow[t]{3}{*}{ Singapore } & $0.05(0.00)^{*}$ & $0.77(0.00)^{*}$ & $0.09(0.00)^{*}$ & -- & $0.02(0.00)^{*}(\mathrm{~L})$ & $0.04(0.03)^{*}(\mathrm{~L})$ & $0.00(0.82)(\mathrm{C})$ & $0.03(0.18)(\mathrm{L})$ \\
\hline & & & & -- & $\phi_{S G-H K}$ & $\eta_{S G-U S}$ & $\gamma_{S G-J P}$ & $\lambda_{S G-U K}$ \\
\hline & & & & -- & $0.01(0.11)$ & $0.01(0.72)$ & $0.02(0.02)^{*}$ & $0.00(0.87)$ \\
\hline \multirow[t]{3}{*}{ Hong Kong } & $0.76(0.00)^{*}$ & $0.35(0.00)^{*}$ & $0.07(0.00)^{*}$ & $0.10(0.00)^{*}(\mathrm{~L})$ & -- & $0.26(0.00)^{*}(\mathrm{~L})$ & $0.04(0.03)^{*}(\mathrm{C})$ & $0.18(0.03)^{*}(\mathrm{~L})$ \\
\hline & & & & $\phi_{H K}-S G$ & -- & $\eta_{H K-U S}$ & $\gamma_{H K-J P}$ & $\lambda_{H K-U K}$ \\
\hline & & & & $0.14(0.00)^{*}$ & -- & $-0.06(0.96)$ & $-0.01(0.80)$ & $-0.03(0.73)$ \\
\hline \multirow[t]{3}{*}{ US } & $0.02(0.00)^{*}$ & $0.87(0.00)^{*}$ & $0.06(0.00)^{*}$ & $0.00(0.15)(\mathrm{L})$ & $-0.01(0.00) *(\mathrm{~L})$ & -- & $0.00(0.41)(\mathrm{C})$ & $-0.00(0.86)(\mathrm{C})$ \\
\hline & & & & $\phi_{U S-S G}$ & $\eta_{U S-H K}$ & -- & $\gamma_{U S-J P}$ & $\lambda_{U S-U K}$ \\
\hline & & & & $0.00(0.90)$ & $0.01(0.00)^{*}$ & -- & $-0.00(0.53)$ & $0.09(0.00)^{*}$ \\
\hline \multirow[t]{3}{*}{ Japan } & $0.21(0.00)^{*}$ & $0.78(0.00)^{*}$ & $0.08(0.00)^{*}$ & $-0.00(0.52)(\mathrm{L})$ & $-0.01(0.39)(\mathrm{L})$ & $-0.03(0.05) *(\mathrm{~L})$ & -- & $0.03(0.13)(\mathrm{L})$ \\
\hline & & & & $\phi_{J P-S G}$ & $\eta_{J P-H K}$ & $\gamma_{J P-U S}$ & -- & $\lambda_{J P-U K}$ \\
\hline & & & & $0.04(0.00)^{*}$ & $-0.00(0.98)$ & $0.04(0.08)^{*}$ & -- & $0.07(0.06)^{*}$ \\
\hline \multirow[t]{3}{*}{ UK } & $0.10(0.00)^{*}$ & $0.70(0.00)^{*}$ & $0.11(0.00)^{*}$ & $0.01(0.00)^{*}(\mathrm{~L})$ & $-0.00(0.28)(\mathrm{L})$ & $-0.01(0.05) *(\mathrm{~L})$ & $0.01(0.05)^{*}(\mathrm{C})$ & -- \\
\hline & & & & $\phi_{U K-S G}$ & $\eta_{U K}-H K$ & $\gamma_{U K-U S}$ & $\lambda_{U K-J P}$ & -- \\
\hline & & & & $-0.01(0.07)^{*}$ & $0.00(0.44)$ & $0.11(0.00)^{*}$ & $0.01(0.11)$ & -- \\
\hline Log-Likel & *Indic & icance at 10 & & & & & & \\
\hline
\end{tabular}

